\title{
EFFECT OF HYDROGEN ON THE CREEP PROPERTIES OF VANADIUM, NIOBIUM AND MOLYBDENUM
}

\author{
John Charles Mather
}

M. S. Thesis Submitted to Iowa State University

\author{
Ames Laboratory, ERDA. \\ Iowa State University
}

Ames, Iowa 50010

This report was puipacice

This report was picpacel as all acuuunt of work sponsored by the United States Government. Neither

the United States nor the United States Energy

Research and Development Administration, nor any of

their employees, nor any of their contractors,

subcontractors, or their employees, makes any

warranty, express or implied, or assumes any legal

liability or responsibility for the accuracy, completeness

or usefulness of any information, apparatus, prot

process disclosed, or represents that its use would not

infringe privately owned rights.

Date Transmitted: February 1975

PREPARED FOR THE U.S. ENERGY RESEARCH AND DEVELOPMENT

ADMINISTRATION UNDER CONTRACT NO. W-7405-eng-82 


\section{DISCLAIMER}

This report was prepared as an account of work sponsored by an agency of the United States Government. Neither the United States Government nor any agency Thereof, nor any of their employees, makes any warranty, express or implied, or assumes any legal liability or responsibility for the accuracy, completeness, or usefulness of any information, apparatus, product, or process disclosed, or represents that its use would not infringe privately owned rights. Reference herein to any specific commercial product, process, or service by trade name, trademark, manufacturer, or otherwise does not necessarily constitute or imply its endorsement, recommendation, or favoring by the United States Government or any agency thereof. The views and opinions of authors expressed herein do not necessarily state or reflect those of the United States Government or any agency thereof. 


\section{DISCLAIMER}

Portions of this document may be illegible in electronic image products. Images are produced from the best available original document. 
This report was prepared as an account of work sponsored by the United States Government. Neither the United States nor the United States Energy Research and Development Administration, nor any of their employees, nor any of their contractors, subcontractors, or their employees, makes any warranty, express or implied, or assumes any legal liability or responsibility for the accuracy, completeness, or usefulness of any information, apparatus, product or process disclosed, or represents that its use would not infringe privately owned rights.

Available from: National Terhnical Information Service U. S. Department of Commerce P.O. Box 1553 Springfield, VA 22161

Price: Microfiche $\$ 2.25$ 

Effect of hydrogen on the creep properties of vanadium, niobium and molybdenum
by

John Charles Mather

A Thesis Submitted to the

Graduate Faculty in Partial Fulfillment of

The Requirements for the Degree of

MASTER OF SCIENCE

Major: Metallurgy

Approved :

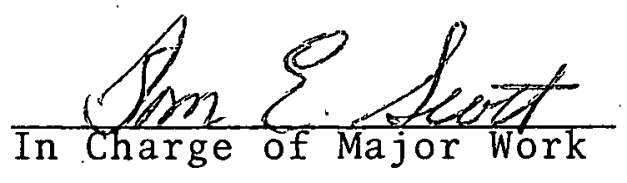

Monract Kechele

For the Major Department

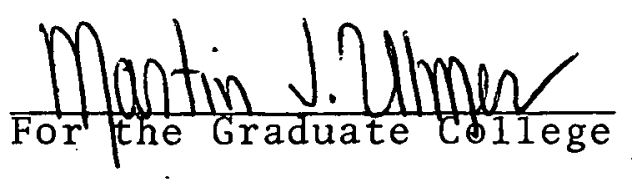

Iowa State University

Ames, Iowa

1975 
TABLE OF CONTENTS,

Page

I. INTRODUCTION 1

A. Purpose of the Present Investigation 2

B. Effects of Test Environment on Creep Data 3

IT. SAMPLE PREPARAITION 6

A. Vanadium 6

B. Niobium 8

C. Molybdenum 9

III. APPARATUS AND EXPERIMENTAL PROCEDURE 11

A. Basic Creep-Test Apparatus 11

B. Data Processing 14

$\begin{array}{ll}\text { C. Perspective } & 19\end{array}$

IV. RESULTS 21

A. Performance of Tcst Apparatus 21

B. Data Processing 24

C. Behavior of Tested Materials 24

V. RECOMMENDATIONS 28

VI. LITERATURE CITED : 32

VII. ACKNOWLEDGEMENTS 34

VIII. APPENDIX A. FIGURES

IX. APPENDIX B. RAW AND PROCESSED NUMERICAL DATA 49

X. APPENDIX C. POLYNOMIAL EXPRESSIONS FOR SHEAR 69 STRAIN $(\gamma)$ AND SHEAR STRAIN RATE $(\dot{\gamma})$ AS FUNCTIONS OF TIME ( $t$ ) IN HOURS 


\section{INTRODUCTION}

A diagram of a conceptual core structure for a Controlled Thermonuclear Reactor (CTR), taken largely from the design of Fraas and Postma ( 1 ), is shown in Figures 1 and 2. Cylindrical walls with struts in the coolant zone have been indicated, but other designs have also been proposed. However, the importance of this figure is not to display specific details, but rather to indicate that the "first wall" will be loaded statically: a liquid metal blanket envelops the wall's exterior and a vacuum exists in the interior. For a reactor of this sort to be useful to society, service life must be measured in years. Therefore, the long-term resistance to deformation under constant load--generally denoted as creep properties--of the materials used in the first wall and at other locations must be known and be compatible with service requirements.

Current designs for projected CTR's are based on the deuterium-tritium (D-T) fuel cycle. The tritium inventory in the breeding blanket, the D-T fuel, plus the protons created in the structural material (particularly the first wall) by $(n, p)$ reactions all combine to present potentially serious material integrity problems. Ultimately, these problems must be surmounted to achieve a successful CTR design. Even without an established design for the projected CTR, it is evident that the effect of hydrogen and its isotopes on the mechanical 
behavior of the first wall material and other structural components is a potential design limiting factor. Unfortunately, essentially no information is available about the effects of tritium or deuterium on the mechanical behavior of materials. Accordingly, it is necessary to assume that the effects of hydrogen will provide a reasonably accurate picture of what problems to expect from its isotopes. Neutronic properties and mechanical strength requirements for the CTR operating temperature range, $600^{\circ} \mathrm{C}$ to $1000^{\circ} \mathrm{C}$, tend to favor vanadium, niobium, molybdenum, or their alloys for the first wail materia1.

A. Purpose of the Present Investigation

The preceding brief background provides the impetus for the nature of, and assists in understanding the scope of, this research. The first need to be met in this research program was to design and construct a test apparatus which would permit evaluation of the effect of hydrogen on the creep properties of candidate CTR first wall refractory materials in the 600 to $1000^{\circ} \mathrm{C}$ temperature range. Accomplishing this was a major step toward the specific goal of determining whether a hydrogen environment significantly affccts the high-temperature creep properties of unalloyed vanadium, ninhium, or molybdenum. 
B. Effects of Test Environment on Creep Data

Intuitively it might be anticipated that creep properties determined in air would differ from creep properties determined in a vacuum. Indeed, differences were found in creep-rupture data for pure nickel tested in air and in vacuum $(2,3)$. These differences were qualitatively explained by a mechanism involving competition between two processes: 1) oxidation strengthening, and 2) enhanced crack propagation due to surface free energy reduction resulting from gas adsorption. Another example is the influence of a growing oxide film on the HerringNabarro creep in magnesium (4).

Even small amounts of common gases in a test environment can contaminate the test material and have a discernible effect on measured properties. Contamination of refractory metal alloys by oxygen and nitrogen can occur under vacuum conditions of $10^{-6}$ Torr: it has been stated that vacuums of better than $1 \times 10^{-8}$ Torr are required to obtain creep measurements which are representative of hasic. material properties $(5,6,7,8)$. For example, the creep strength of $\mathrm{Nb}-0.6 \mathrm{zr}$ was found to be strongly dependent on test vacuum in the range $10^{-5}$ to $10^{-7}$ Torr (9). This dependence was attributed to effects of contamination from residual gases. Nitrogen and oxygen have been shown to improve creep-rupture strength of niobium for tcmperatures $<0.5 \mathrm{~T}_{\mathrm{m}}(10)$; and oxygen, carbon, and nitrogen as interstitial species have shown a marked effect on creep strength 
of $\mathrm{Nb}-\mathrm{Mo}$ alloys (11).

Because of the above sensitivity of creep properties of refractory metals to even small amounts of contaminants in the test environment, much of the data available from the 1iterature may be only marginally useful relative to this study. In many cases the gas pressure under which tests were conducted was greater than $1 \times 10^{-8}$ Torr. In the cases where inert gas atmospheres were used it is likely that the "pure" inert gas contained impurity bases at levels far in excess of what would be present in a vacuum of $1 \times 10^{-8}$ Torr.

Disregarding these finer details of test environment, there is meagre data relating to the effect of the presence of hydrogen on creep properties of engineering materials. The creep strength of Inconel was found to be less in hydrogen than in argon at 704 and $815^{\circ} \mathrm{C}$ (12). Similar results were found for Nickel 200, Nickel 270, electron-beam zone-refined nickel and high purity copper (13). An abundance of elongation and reduction in area data from tensile tests has established that niobium and vanadium are catastrophically embrittled by relatively low concentrations of dissolved hydrogen near room temperature. Evidence also indicates that molybdenum is not embrittled by hydrogen at low temperatures $(9,14)$. The effects of hydrogen at low pressures $(<1$ Torr) on metals at temperatures in the CTR operating range are virtually unexplored. By extrapolating from data in the low temperature range, it is speculated that substantial hydrogen 
concentrations would be necessary to produce a ductile-tobrittle transition in niobium or vanadium at CTR operating conditions. For example, extrapolation predicts that about 36 atom per cent (600.0 ppmw) hydrogen.in niobium and about 93 atom per cent $\left(2 \times 10^{5} \mathrm{ppmw}\right)$ in vanadium would be required to raise the DBTT to the CTR temperature range. It is not likely that these concentrations of hydrogen could be attained from the anticipated hydrogen gas pressures of $10^{-6}$ to $10^{-3} \mathrm{Torr}$ at or near the first wall.

Insufficient information is available to predict what the hydrogen pressure dependence of the creep behavior of these materials might be. However, McCoy and Douglas (15) found the creep rate of niobium stressed to $3500 \mathrm{psi}$ at about $980^{\circ} \mathrm{C}$ to be greatly accelerated by moist or dry hydrogen flowing at 0.2 cfh as shown in Figure 3 . Therc is no established mechanism to explain this modification of creep behavior in the presence of hydrogen. . It may be due to a hydrogen-impurity interaction which weakens the grain boundaries, hydrogen reduction of strengthening surface oxide films or some unexplored mechanism. 


\section{SAMPLE PREPARATION}

\section{A. Vanadium}

The vanadium metal used in this investigation was originally prepared by the iodide refining process described by Carlson and Owen (16). The material was cut from a 1/4-inch diameter rod which had been cold-swaged from ingot form. Chemical analysis of the metal appears as Table 1 . Oxygen, nitrogen, and hydrogen concentrations were determined by the vacuum fusion method. The metaliic impurities were determined by spectrographic analysis.

Table 1. Chemical analysis of vanadium

\begin{tabular}{crcr}
\hline Element & Content, ppm & Element & Content, ppm \\
\hline $\mathrm{Cr}$ & $<5,000$ & $\mathrm{Ti}$ & $<40$ \\
$\mathrm{Cu}$ & $<200$ & 0 & 400 \\
$\mathrm{Fe}^{\mathrm{n}}$ & $<5,000$ & $\mathrm{H}$ & 2 \\
$\mathrm{Ni}$ & $<2,000$ & $\mathrm{~N}$ & 140 \\
$\mathrm{Si}$ & $<400$ & & \\
\hline
\end{tabular}

Processing the material into its ultimate helical shape was a multi-step procedure, the highlights of which are elucidated below.

1. Major reduction was by cold-swaging. The swaging sequence used was adapted from the work done by Sherman (17). Each step in the swaging process 
reduced the entering cross-sectional area by 60 to 70 per cent. Details are given in Table 2 below.

2. To ensure uniform specimen conditions at the start of each test, it was decided that in-situ anneals would be performed prior to load application. The small amount of plastic strain introduced while wrapping a wire into the helix-configuration could cause undesirable grain size and/or grain size gradients in the sample after annealing. To ensure uniform grain size, and to make the wires easier to handle during cleaning and wrapping, they were uniaxially strained, approximately eight per cent in a tensile test machine prior to final cleaning and wrapping into helices.

3. The chomical cleaning sequence always started with a wash in trichloroethane and rinse.in acetone (for oil and grease removal). Actual "etching" was done in a $50 / 50$ by volume $\mathrm{HNO}_{3} / \mathrm{H}_{2} \mathrm{O}$ solution at room temperature. Doing this with straight wires rather than helices was found to give more uniform material removal. Chemical cleaning was followed by a water rinse, acetone rinse, and dry.

4. The helical shape was achieved by individually wrapping each wire around a piece of 1/4-20 UNC threaded rod. This "mandrel", covered with Teflon tape for protection of the sample surfacc, was chucked in a 
lathe and rotated by hand. Because of the initially straight wires and the type of mandrel used, the helix pitch and coil straightness were fairly consistent.

Table 2. Swage/anneal sequence.

\begin{tabular}{|c|c|c|c|c|}
\hline Operation & $\begin{array}{l}\text { Starting } \\
\text { diameter }\end{array}$ & $\begin{array}{l}\text { Final } \\
\text { diameter }\end{array}$ & $\begin{array}{l}\frac{\circ}{6} \text { Area } \\
\text { reduction }\end{array}$ & Comment \\
\hline Annea 1 & 0.250 & 0.250 & $\cdots$ & $\begin{array}{l}1000^{\circ} \mathrm{C} \text { for } 4 \text { hours } \\
0<10^{-6} \text { Torr }\end{array}$ \\
\hline Swage & $\begin{array}{l}0.250 \\
0.230 \\
0.187 \\
0.150 \\
0.125\end{array}$ & $\begin{array}{l}0.230 \\
0.187 \\
0.1 .50 \\
0.125 \\
0.100\end{array}$ & $\begin{array}{l}\cdots \\
0.662 \\
0.643 \\
0.693 \\
0.640\end{array}$ & \\
\hline Anneal & & -- & $\ldots$ & $1000^{\circ} \mathrm{C}$ for 4 hours \\
\hline Swage & $\begin{array}{l}0.100 \\
0.078 \\
0.063 \\
0.051 \\
0.040\end{array}$ & $\begin{array}{l}0.078 \\
0.063 \\
0.051 \\
0.040 \\
0.031\end{array}$ & $\begin{array}{l}0.608 \\
0.652 \\
0.655 \\
0.615 \\
0.601\end{array}$ & \\
\hline Anneal & - . - & $\ldots$ & - - & $1000^{\circ} \mathrm{C}$ for 4 hours \\
\hline
\end{tabular}

B. Niobium

The niobium metal used in this investigation was obtained in the form of annealed 1/4-inch thick sheet from the Metals Division of Fanstee1, Inc. Manufacturer's analysis (ingot) is given in Table 3 below.

A $1 / 4 \times 1 / 4 \times 5$-inch piece was cut from the sheet, and its edges were generously rounded to allow swaging without producing folds in the material. The cleaning operations were the same as given above for vanadium, except the polishing solution consisted of $40 / 40 / 20$ per cent by volume of 
$\mathrm{HNO}_{3} / \mathrm{H}_{2} \mathrm{SO}_{4} / \mathrm{HF}$ respectively. Major reduction was by cold swaging, as described for vanadium in the previous section. The initial anneal was not required because the material was received in the annealed condition. Intermittent anneals were at $1100^{\circ} \mathrm{C}$ for two hours. The pre-straining and wrapping procedures were the same as for vanadium.

Table 3. Chemical analysis of niobium

\begin{tabular}{cccccc}
\hline Element & $\begin{array}{c}\text { Content, } \\
\text { ppm }\end{array}$ & Element & $\begin{array}{c}\text { Content, } \\
\text { ppm }\end{array}$ & Element & $\begin{array}{c}\text { Content, } \\
\text { ppm }\end{array}$ \\
\hline $\mathrm{C}$ & $<10$ & $\mathrm{Fe}$ & $<50$ & $\mathrm{~V}$ & $<20$ \\
0 & 31 & $\mathrm{Ni}$ & $<20$ & $\mathrm{Co}$ & $<10$ \\
$\mathrm{~N}$ & 27 & $\mathrm{Si}$ & $<50$ & $\mathrm{~B}$ & $<1$ \\
$\mathrm{H}$ & $<5$ & $\mathrm{Mn}$ & $<20$ & $\mathrm{Cd}$ & $<5$ \\
$\mathrm{Ta}$ & 560 & $\mathrm{Ca}$ & $<20$ & $\mathrm{Mg}$ & $<20$ \\
$\mathrm{~W}$ & $<100$ & $\mathrm{Al}$ & $<20$ & $\mathrm{~Pb}$ & $<20$ \\
$\mathrm{Zr}$ & $<50$ & $\mathrm{Cu}$ & $<20$ & $\mathrm{Hf}$ & $<100$ \\
$\mathrm{Mo}$ & $<50$ & $\mathrm{Sn}$ & $<20$ & $\mathrm{Nb}$ & $\mathrm{Ba} 1$ ance \\
$\mathrm{Ti}$ & $<20$ & $\mathrm{Cr}$ & $<20$ & & \\
\hline
\end{tabular}

C. Molybdenum

The molybdenum used in this investigation was procured as a spool of 0.030-inch diameter wire, labeled "commercially pure". Chemical analysis of the metal is given in Table 4. Oxygen, nitrogen, and hydrogen concentrations were determined by the vacuum fusion method. The metallic impurities were determined hy spectrographic analysis.

After being cut to length, each wire was prestrained approximately six per cent for straightness and for introduction of cold-work, as before. This was followed by the clean- 
ing sequence given for vanadium, except that the chemical etchant was 50 parts $\mathrm{HF}$ to 50 parts $\mathrm{HNO}_{3}$ by volumé. Wrapping the wires into helices was as given for vanadium.

Table 4. Chemical analysis of molybdenum

\begin{tabular}{crcc}
\hline Element & Content, ppm & Element & Content, ppm \\
\hline $\mathrm{Cr}$ & $<2,000$ & $\mathrm{Si}$ & $<3,000$ \\
$\mathrm{Cu}$ & $<200$ & $\mathrm{Ti}$ & $<40$ \\
$\mathrm{Fe}$ & $<30,000$ & 0 & 38 \\
$\mathrm{Mn}$ & $<1,000$ & $\mathrm{H}$ & $<1$ \\
$\mathrm{Ni}$ & $<3,000$ & $\mathrm{~N}$ & 2 \\
\hline
\end{tabular}


III. APPARATUS AND EXPERIMENTÁL PROCEDURE:

\section{A. Basịc Creep-Test Apparatus}

As delineated in the Introduction, the purpose of this research was to obtain data such that the effects of a hydrogen atmosphere on creep properties could be ascertained. The temperature range of interest is approximately 900 to $1300^{\circ} \mathrm{K}$ : the estimated temperature range to be endured by the "first wall" of a fusion reactor. Determination of "base" data required a vacuum of better than $1 \times 10^{-8}$ Torr, and the system needed to be as free from vibration as possible.

The combination of high vacuum and high temperature made direct electronic readout of sample elongation unfeasible for several reasons:

1. Transducers able to operate anywhere near the test Lemperatures were not readily available.

2. Using vacuum-tight bellows as "feedthroughs" to connect samples to load and transducers is fraught with problems of calibration of the bellows for its spring factor as a function of position (K-factor of the bellows alone), barometric pressure, and quality of vacuum.

3. Use of external electronic transducers reduces the flexibility of the test apparatus as regards sample loading, placement of electric furnace element and power feedthroughs, temperature sensors, and thermal shieiding. 
A logical alternative to electronic readout is optical measuring of sample elongation. An opticà cathetometer was procured: its scale showed a least count of 0.05 millimeters. Obtaining good resolution of sample strain. with this device required that the samples be quite long. Proper sample length was obtained by having the specimen assume a helical shape.

Based on information in the Introduction and in the above, the general design criteria for the test apparatus can be itemized as follows:

1. HIGH VACUUM is required for elimination of contaminating interstitials from the environment around the samples, and from the surfaces of the samples themselves.

2. HIGH TEMPERATURE capability was required for in-situ anneals of all materials being used. This criterion, plus the need to sustain high temperatures for long test periods dictated that the heater be inside the vacuum chamber rather than an external split-furnace in a muffle arrangement.

3. OPTICAL READOUT of sample elongation required that a view-port be part of the system. A rotatable shield was installed to protect the viewport from intense heat radiated during the in-situ anneals.

4. SIMULTANEOUS TESTING OF SEVERAL SAMPLES was desirable because of the long-term nature of creep tests. The chamber was made of a size which would allow for 
three "columns" of samples to be tested concurrently. Each column could contain either one or two samples-it was found that more than two samples in any one column caused axial alignment problems.

5. ANNEALING IN-SITU required a method for loading and unloading the samples such that the anneal could proceed with samples unloaded, and that the load could be applied after completing the anneal and stably attaining the test temperature. This requirement was really quite difficult since at the temperatures and vacuum used, sintering was a problem between the "prop" used for weight removal and the base which the "prop" contacted.

6. Use of hydrogen as a test environment made material selection a problem because of possible brittle hydride formation during test. Also, vacuum gages had to be judiciously placed such that readings could be taken during hydrogen runs when the vacuum pump. would be sealed from the test chamber. Because bottled hydrogen gas or hydrogen obtained by exothermic decomposition of uranium hydride could contain substantial impurities, a purification "membrane" of palladium-25 silver was installed in the system. Bottled hydrogen could then be used as the gas source. 
An annotated photograph of the complete test apparatus appears as Figure 4. Figure 5 is a detailed "cutaway" view similar to the photograph, showing some of the internal parts. It can be seen that the physical aspects of the design criteria have been fulfilled.

\section{B. Data Processing}

Raw data compiled for each test instance ${ }^{1}$ included information about the test environment, the sample, and the behav: ior of the sample. The following items were recorded for each sample as it was assembled into the test rig: wire diameter, helix diameter, number of active turns, and load. When pressure and temperature conditions stabilized, data for the plots were taken. This consisted of noting the date, the time of day, the position of a characteristic point on the sample holder at the top of the sample, and the position of a characteristic point on the weight attached to the bottom of the sample. System pressure and temperature were recorded each time positional data were taken.

A large amount of the computational work required in this investigation was performed with the aid of a digital computer. A program was developed sur.h that. its output would be a complete record for each test instance. Expressions for the primary items of interest in the output are developed and

${ }^{1}$ A test instance is determined by assigning a value to each of the four major variables: material, temperature, stress leve1, and envirominent. 
discussed in detail below.

Figures $6 \mathrm{a}$ and $6 \mathrm{~b}$ depict a helical spring and the wire in the spring, respectively. The symbols and parameters used to: describe the stress state and strain condition of a test specimen are given in Table 5 .

The maximum surface shear stress in the coil at the start of the test was calculated using accepted equations for torsional stress, adapted to helical coils.

$$
\begin{aligned}
\tau & =K\left[\frac{T r}{J}\right] ; \text { or } \tau_{\max }=K\left[\frac{T_{\text {max }}}{J}\right] \\
\tau_{\max } & =K\left[\left(\frac{P D}{2}\right)\left(\frac{d}{2}\right)\left(\frac{32}{\pi d^{4}}\right)\right] \\
\tau_{\max } & =K\left[\left(\frac{8}{\pi}\right)\left(\frac{P D}{d^{3}}\right)\right]
\end{aligned}
$$

Propagation of erior lechniques were employed to determine an expression for the uncertainty in the computed stress (18).

$$
\begin{aligned}
& \omega_{\tau_{\max }^{2}}^{2}=\left(\frac{\partial \tau}{\partial K}\right)^{2}{ }^{\prime \prime \prime}{ }_{K}^{2}+\left(\frac{\partial \tau}{\partial P^{2}}\right)^{2}{ }^{2}{ }_{P}^{2}+\left(\frac{\partial \tau}{\partial D}\right)^{2} \omega_{D}^{2}+\left(\frac{\partial \tau}{\partial d}\right)^{2} \omega_{d}^{2} \\
& \omega_{\tau_{\max }}^{2}=\left(\frac{8 P D}{\pi d^{3}}\right)^{2} \omega_{K}^{2}+\left(\frac{8 D K}{\pi d^{3}}\right)^{2} \omega_{P}^{2}+\left(\frac{8 P K}{\pi d^{3}}\right)^{2} \omega_{D}^{2}+\left(\frac{-24 K P D}{\pi d^{4}}\right)^{2} \omega_{d}^{2}
\end{aligned}
$$

Relating shear strain to measured elongation of the sample was computed using the expressions developed below.

Consider the wire in Figure $6 \mathrm{~b}$.

$$
L d \gamma=r d \alpha=\frac{d}{2}(d \alpha)
$$


Table 5. Nomenclature for sample geometry; stress state and strain condition

\begin{tabular}{|c|c|c|c|c|}
\hline Symbol & Definition & Expression & $\begin{array}{c}\text { Approx. } \\
\text { nom: } \\
\text { value }\end{array}$ & $\begin{array}{l}\text { Max. } \\
\text { error } \\
\text { (est) } \\
\end{array}$ \\
\hline $\mathrm{d}$ & Wire diameter & $-\cdots$ & $0.787 \mathrm{~mm}$ & $0.03 \mathrm{~mm}$ \\
\hline $\mathrm{r}$ & $\begin{array}{l}\text { Distance from neutral axis to point } \\
\text { of interest: thus } r_{\max }=\mathrm{d} / 2\end{array}$ & $\cdots$ & --- & $\cdots$ \\
\hline $\mathrm{J}$ & $\begin{array}{l}\text { Polar noment of inertia for wire } \\
\text { cross-section area }\end{array}$ & $\pi d^{4} / 32$ & --- & $-\cdots$ \\
\hline $\mathrm{P}$ & Axial load, grams & $\cdots$ & --- & $1.0 \mathrm{gm}$ \\
\hline $\mathrm{D}$ & $\begin{array}{l}\text { Helix diameter from center } 1 \text { ine to } \\
\text { center line of the wire }(O D-d / 2)\end{array}$ & $-\cdots$ & $7.1 \mathrm{~mm}$ & $0.15 \mathrm{~mm}$ \\
\hline $\mathrm{T}$ & $\begin{array}{l}\text { Torque or moment applied to wire } \\
\text { in spring }\end{array}$ & $P(D / 2)$ & $-\cdots$ & --- \\
\hline $\mathrm{N}$ & Number of active turns in the helix & --- & 10 turns & 0.1 turn \\
\hline $\mathrm{L}$ & "Active length" of wire in helix & $\pi \mathrm{DN}$ & $-\cdots$ & --- \\
\hline$y, \Delta$ & Axial coil deflection & $-\cdots$ & --- & $0.2 \mathrm{~mm}$ \\
\hline $\mathrm{K}$ & $\begin{array}{l}\text { Stress concentration factor } \\
(C=D / d)\end{array}$ & $\frac{4 C-1}{4 C-4}+\frac{0.615}{C}$ & 1.162 & $0.117^{a}$ \\
\hline $\mathrm{h}$ & $\begin{array}{l}\text { Spacing of adjacent turns in } \\
\text { helix }\end{array}$ & $\cdots-$ & $1.27 \mathrm{~mm}$ & $.38 \mathrm{~mm}$ \\
\hline
\end{tabular}

${ }^{a}$ Computed by separate propagation of error analysis. 


$$
\text { or } \quad \mathrm{d} \gamma \doteq\left(\frac{\mathrm{d}}{2 \mathrm{~L}}\right) \mathrm{d} \alpha
$$

But the load $\mathrm{P}$ has a moment arm (D/2), so the differential deflection $d y$ is as follows:

$$
\text { or } \begin{aligned}
(d Y) & =(d \alpha)(D / 2) \\
(d \alpha) & =(2 d Y) / D
\end{aligned}
$$

Then, $d \gamma=(d / 2 L)(2 d Y / D)=d(d Y) / L D$.

Now an expression must be developed to relate the extension of the helix to actual helix diameter. Take a helical coil and "unwind" it, keeping proper relationships with respect to its axis as illustrated in Figure 7 .

From the figure, the following relationships are apparent:

$$
\begin{aligned}
& \mathrm{L} \sin \theta=\mathrm{Y} \\
& \mathrm{L} \cos \theta=\mathrm{ND} \pi
\end{aligned}
$$

Then, squaring and adding,

$$
\text { or } \quad \begin{aligned}
I^{2} & =Y^{2}+(N D \pi)^{2} \\
D^{2} & =\left(L^{2}-Y^{2}\right) /(\pi N)^{2}
\end{aligned}
$$

Then the expression for dy becomes:

or

$$
d Y=\left(\frac{d}{L}\right) \frac{d Y}{\left[\frac{L^{2}-Y^{2}}{(\pi N)^{2}}\right]}=\left[\frac{\pi N d}{L}\right]\left[\frac{d Y}{\left(L^{2}-Y^{2}\right)^{1 / 2}}\right]
$$

$$
\gamma=\left[\frac{\pi N d}{L}\right] \int_{Y}^{Y} \frac{d Y}{\left(L^{2}-Y^{2}\right)^{I / 2}}
$$


From integration tables,

$$
\int \frac{d u}{\left[a^{2}-u^{2}\right] 1 / 2}=\sin ^{-1}\left(\frac{u}{a}\right)+c
$$

Therefore:

$$
Y=\left[\frac{\pi N d}{L}\right]\left[\sin ^{-1}\left(\frac{Y}{L}\right)-\sin ^{-1}\left(\frac{Y}{L}\right)\right]
$$

Or, in terms of measured data;

$$
\begin{aligned}
\gamma= & {[\pi d]\left[\pi^{2} D_{0}^{2}+h_{o}^{2}\right]^{-1 / 2}\left\{\sin ^{-1}\left[\left(h_{0}+\Delta N^{-1}\right)\left(\pi^{2} D_{0}^{2}+h_{0}^{2}\right)^{-1 / 2}\right]\right.} \\
& -\sin ^{-1}\left[\left(h_{0}\left(\pi^{2} D_{0}^{2}+h_{o}^{2}\right)^{-1 / 2}\right]\right\}
\end{aligned}
$$

Computation of uncertainty limits on shear strain is similar to that given previously for stress.

Employing the expressions developed above, a shear stress level and its uncertainty were computed utilizing the raw data for each test instance. Additionally, a shear strain value was computed for every data point recorded, and the maximum uncertainty in the shear strain was determined. A linear least squares regression (18) of strain on time was performed on those data values judged to be in the region of secondary creep. In addition to providing the equation of the best-fit straight line, the computer subroutine used for this regression utilizes the uncertainty in the strain values and the randomness of the data points about the best-fit line to compute and output values of several statistical parameters for each data set. These parameters are required if the $F-t e s t$ and the $t$ test are used to determine whether the presence of hydrogen 
has a significant effect on the secondary creep rate of the samples being compared.

While plots of shear strain versus time are enlightening and allow comparison of material performance, it was found that plots of strain rate versus strain assist greatly in making those relative comparisons. To obtain the latter plot, several polynomial functions were first fitted to each shear strain versus time plot. The lowest order curve which adequately fit the data, usually fourth or fifth order, was selected for each test instance. Its derivative was determined and evaluated at several values of time for which strain values had also been determined.

\section{Perspective}

Because of the creep condition, the helix diameter (D) and the wire diameter (d) varied during the test period. In addition, the stress condition varied throughout the helix, and therefore the amount of relaxation occurring during the test also varied from location to location within the sample. The stress condition in the wire and the location of the neutral axis of the test piece varied as a function of location in the sample and as a function of time for each location. Even though a rather detailed analysis of stress distribution during creep testing of helical spring specimens has been accomplished (19), it will not be considered here because it was not required for this research. The real concern of this 
investigation was to determine whether the presence of hydrogen significantly affects creep properties of the subject materials, with secondary creep rate being the key property under study. To ascertain this, the only data actually required for each test instance was "percent elongation versus time". The data reported herein are in units of strain for convenience in comparing with published data.

To ensure legitimate comparisons and accurate conclusions, many precautions were taken. Among those are the following. Samples to be compared were loaded as closely as possible to the same stress level, and were located in the same place inside the test apparatus to avoid effects of temperature gradients. Compared sets of samples also received the same thermal history. 
IV. RESULTS

A. Performance of Test Apparatus

It was found that a significant amount of time was required to get from the design concept stage to a satisfactory operational mode. Before any useful test data was obtained, Inany problems unforeseen in the initial design concept had to be solved. Several problems originally considered to be minor were not, and also had to be overcome.

It was found that the original method for applying load to the test specimens would not work satisfactorily. The final design of the sample holder consisted of a square-threaded screw onto which the helical sample is threaded. This method is very convenient.

Sintering problems were encountered. Most of the test apparatus exposed th the high test and annealing temperatures is fabricated from 304 stainless steel. At the specimon annealing temperature of $1100^{\circ} \mathrm{C}$ this material will easily sinter to itself, to niobium, and to vanadium, if sufficient force is present. Where possible, wafers or sheets of tungsten were judiciously placed to avoid stainless-to-stainless contact. In other cases it was determined that sintering did not affect the test, but did create problems during sample loading and unloading because of the tendency for galling to occur after the initial sintered joint was broken. This tendency is a result of the extremely clean surface present, and 
can be reduced substantially by flooding the joints with methyl alcohol prior to unscrewing. This wets the potential galling surface and acts as a lubricant during assembly and disassemb1y. Methyl alcohol is chosen because it evaporates easily and volatile residuals are pumped adequately by the ion pump.

While a Titanium Sublimator Pump (TSP) significantly augments the pumping speed of a standard ion pump, it was found that the TSP must be shielded from the main test chamber. Figure 4 shows the location of the TSP at the lower end of the test chamber, just above the large gate valve. When operated in this location, a fairly thick layer of titanium condenses on the system walls just above the valve, and a much finer layer is condensed on the remainder of the chamber walls. When hydrogen is admitted to the test chamber, there is so much titanium surface and mass available that an equilibrium pressure of hydrogen could not be reached even after over 12 hours of steady hydrogen input. Additionally, the hydrided titanium flaked off of the chamber walls and fe11. to the bottom of the system. When an attempt to pump a respectable vacuum on this system was made, the titanium hydride outgassed severely, especially when external heat was applied.

With the interior of the system thus contaminated, a complete disassembly and cleanup was required.

Upon reassembly and repair of a leak precipitated by the 
acid cleaning procedure, very good vacuum performance was achieved. After bakeout, pumpdown to better than $2 \times 10^{-9}$ Torr was achieved with the system cold. As expected, vacuum levels. deteriorate rapidly due to outgassing as system temperature increases. However, vacuum levels during the $900^{\circ} \mathrm{C}$ test were generally near $5 \times 10^{-8}$ Torr or better, indicating an acceptably clean system.

After new samples are loaded into the test apparatus, the chamber is pumped down and baked out. After a satisfactory vacuum level is reached, the system wall is cooled and the samples are annealed in situ. The system is then brought to test temperature. For a vacuum test run, the samples are lifted into place and data recording commences as soon as test temperature is reached.

For a test run in a hydrogen environment the procedure after reaching test temperature is as follows. The ion pump is isolated from the test chamber. The system is allowed to sit in this static condition for from one to five minutes until a "base" static vacuum level is reached. Commercial hydrogen gas from a large cylinder is admitted to the opening of the Pd-Ag tube which serves as a hydrogen purifier. Purified hydrogen is admitted to the chamber until the desired pressure is read on the ion gage or until the range of the ion gage is exceeded. When the desired hydrogen pressure is reached, the samples are lifted into place and data recording commences. 
The power source for the furnace element supplies alternating current power. It was found in one test that one sample was sympathetic to the $120 \mathrm{~Hz}$ vibration generated in the large conductors carrying the 300-plus ampere current. It is felt that this problem did not have a detrimental effect on the data obtained. However, inexpensive methods of eliminating the problem are being investigated.

Reading the position of the samples with the optical cathetometer provided a convenient and sensitive method of data collection. It was found that the least count on the cathetometer was smaller than the error of this human's eye in placing the cross-hairs on a desired location.

\section{B. Data Processing}

The computer program written for processing of raw creep data into a complete test record is well documented and convenient to use. The program includes a subroutine to fit the best straight line through selected data points, as designated by the user. An additional program to fit a polynomial to the creep curve was utilized in preparing Figures 10 and 12 . It is intended that these programs be fully combined into a complete data analysis package to achieve unbiased curve-fitting and statistical comparison of future data sets.

\section{Behavior of Tested Materials}

The expressed purpose of this research project was to ascertain whether the presence of hydrogen affects the creep 
properties of unalloyed vanadium, niobium, and molybdenum metals. Plots of each metal's creep performance at $900^{\circ} \mathrm{C}$ in vacuum and in hydrogen are given in Figures 8,9 , and 11 . The pressure level during the vacuum run was approximately $5 \times 10^{-8}$ Torr: the hydrogen pressure level during the hydrogen environment run was between one atmosphere and $1 \times 10^{-3}$ Torr, over a "base" static vacuum of $1 \times 10^{-6}$ Torr. Raw and processed numerical data are contained in Appendix B; polynomial expressions for shear strain and shear strain rate as functions of time are presented in Appendix C.

Figure 8 shows the results for niobium. It is apparent that, for the $900^{\circ} \mathrm{C}$ test temperature, the stress level was far too low to produce a suitable creep curve. Indeed, the ordinate axis is shear strain $\times 10^{4}$ : only $5 \times 10^{-4}$ strain was reached after 500 hours. In fact, the resolution of the instrumentation can be seen in the data as plotted: note the discrete increments in strain yalues. These data are of little significance except to indicate that under the conditions and time limits imposed, the presence of hydrogen has no effect on the creep rate of niobium. But the conditions and/or time limits imposed are not considered proper.

Figure 9 displays the creep curves obtained for molybdenum in vacuum and in hydrogen. As expected, the hydrogen environment data overlay the vacuum data almost exactly. The hydrogen data lie wholly beneath the vacuum data for times greater than 250 hours, but the difference is very sma11 and 
the straight lines through those points of the respective curves appear nearly parallel. Indeed, Figure 10 illustrates that strain rate as a function of strain behaves nearly identically for both environments. The curve shapes are similar and each curve has a minimum in the neighborhood of $3.7 \times 10^{-3}$ strain. Additionally, the minimum strain rates are quite close to each other. It is suggested that these results support the conclusions by other researchers that the presence of hydrogen has little or no effect on the creep properties of molybdenum, at least under the prevailing test conditions.

The results obtained for vanadium are by far the most dramatic and exciting. It should be noted that the range of shear strain covered was the greatest of all samples tested. It is also important to observe that the character of the curve for hydrogen-environment data is different from that for the vacuum data. The slopes in the central and final portions of the hydrogen curve are steeper than for comparative locations on the curve for the test run in vacuum. Extension to $3.9 \%$ strain was achieved 120 hours sooner, or $27 \%$ faster, in hydrogen than in vacuum. The plot of strain rate versus strain in Figure 12 vividly displays the differences in the creep curves. The strain rate of the vacuum data does not appear to have reached a constant value during the time span of the test, but the hydrogen data shows a leveling off at the end of the test period. This suggests that the hydrogen environment enhances creep, because second stage is reached more rapidly in this 
environment than in vacuum. Additionally, there is a substantial difference between the final values of strain rate for the two curves: the rate for the hydrogen is nearly three times that of the vacuum data. It appears that the presence of hydrogen does have an effect on the creep properties of vanadium metal. The results presented here warrant conducting more research. 


\section{RECOMMENDATIONS}

The real value of this research effort lies in the design, construction, and successful operation of a sensitive creep test apparatus; the development of a computer program and other related procedures for data analysis; and in the accrual of data which indicate that a hydrogen environment affects creep, thereby substantiating the need for extensive investigation of the phenomenon.

In the two-plus years since the start of this project, many things have happened which can be attributed to lack of experience with high vacuum/high temperature test equipment and procedure. While two years' experience is not sufficient. qualification for "expert" status, there are several.changes which, in the researcher's opinion, should be made to the test apparatus and experimental procedure to improve overall capability, flexibility, and efficiency.

The first recommendation, however, is not one regarding the system but rather one concerning the data generated. It is assumed that concentration will at least temporarily turn to vanadium, since it appeared to react most dramatically to the presence of hydrogen. In order to have confidence in the data presented herein, they should be confirmed by more tests at the same conditions. It is suggested that three additional samples be loaded to the proper stress level: and tested in vacuum and in hydrogen. With this amount of data, a statisti- 
cal comparison ( $t$-test) of the hydrogen and vacuum environment data can be made, and some unbiased conclusions may be drawn from the statistical analysis.

As additional tests are conducted it will become increasingly important to obtain accurate measurements of the following parameters: helix diameter $\left(D_{0}\right)$, wire diameter (d), number of active turns $(\mathrm{N})$, advance per turn $\left(\mathrm{h}_{\mathrm{o}}\right)$, load, and deflection. As experience is gained regarding their measurement, the error limits on their values should be closely examined to determine if the error limits written into the computer program can be reduced. These error, or uncertainty, values enter into statistical computations in the least squares best fit straight line subroutine, and will affect the user's ability to ascertain significant differences between minimum creep rates.

The helix should be appropriately proportioned so the load required for the desired stress level is much greater than the weight of the sample. This will minimize the effect of the stress gradient in the sample due to sample weight relative to nominal stress level.

It is recommended that several changes be made to the test apparatus and associated hardware:

- To ensure that samples will easily assemble into their holders, a square-threaded mandrel identical to the holders should be fabricated for use in sample preparation. 
- Since sample geometry is fairly consistent and only minor variations occur in critical dimensions, the loading weights should be redesigned to allow minor changes in their total mass to be made conveniently and quickly.

- A method should be devised to reduce the possibility of vibration excitation of the test chamber from the furnace power supply. The best--but probabiy the most expensive-solution would be to procure a DC power supply.

- System components should be rearranged as necessary to allow incorporation of a titanium sublimator pump which would be shielded from the main chamber and valved-off during hydrogen runs. This change will increase pumping speed and thus reduce the time required for system bakeout, as well as maintain superior vacuum levels during sample anneal and high-temperature vacuum test runs.

- Obtain a gage with high vacuum integrity to measure system pressure in the range $10^{-1}$ to $10^{-6}$ Torr. Standard ion gages are not usable above $1 \times 10^{-3}$ Torr, and thermocouple-type vacuum gages do not have sufficient integrity to allow high vacuums to be pumped on them.

- The amount of hydrogen admitted to the system, as measured by system pressure, cannot presently be controlled accurately. It is felt that a manual system would not allow the continuous monitoring and control which will ultimately be required for test runs to determine crecp 
properties as a function of hydrogen pressure. Equipment to accurately control the pressure of the chosen environment should be procured. 


\section{LITERATURE CITED}

1: Fraas, A. P. and Postma, H., USAEC Report ORNL-TM-2822, Oak Ridge National Laboratory, Oak Ridge, Tennessee, Nov. 1970 .

2. Stegman, R. L., Shahinian, P., and Achter, M. R., Trans. Met. Soc. AIME, 245, 1759 (Aug. 1967).

3. Shahinian, P. and Achter, M. R., Trans. Met. Soc. AIME, 215, 37 (Feb. 1959).

4. Hales, R., Dobson, P. S., and Smallman, R. E., Acta Met., 17,1323 (Nov. 1969).

5. Sawyer, J. C., and Steigerwald, E. A., J. Mater., 2, no. 2, 341 (June 1967).

6. Inouye, H., USAEC Report ORNL-3674, Oak Ridge National Laboratory, Oak Ridge, Tennessee, September 1964.

7. Bourgette, D. T., Trans. Vac. Met. Conf., 8, 57 (1965).

8. Buckman, R. W., Jr., Trans. Vac. Met. Conf., 9; 25 (1966).

9. Schmidt, F. F., Maykuth, D. J., and Ogden, H. R., DMIC Report 205, Defense Metals Information Center, Battelle Memorial Institute, Columbus, Ohio, August 20, 1966.

10. Stoop, J. and Shahinian, P., ASM Trans. Quart., 39, 411 (1966).

11. Jackson, R., Carvalhinhos, H. J., and Argent, B. B., J. Inst. Metals, 96, 210 (1968).

12. Douglas, D. A., in "High Temperature Materials", Hehemann, R. F. and Ault, G. M., eds., John Wiley and Sons, New York, 1959, p 429 .

13. McCoy, H. E., Jr., Effects of Hydrogen on the High Temperature flow and Fracture Characteristics of Metals. Ph.D. Thesis, University of Tennessee, June 1964.

14. Mach1in, I., J. Metals, 20, no. 9, 21 (Sept. 1968).

15. McCoy, H. E., Jr. and Douglas, D. A., in "Columbium Metallurgy", Douglass, D. L. and Kunz, F. W. , eds., Interscience Publishers, New York, 1961, p 85. 
16. Carlson, 0. N. and Owen, C. V., J. E1ectrochem. Soc., $108,88-93$ (1961).

17. Sherman, D. H., An Investigation of the Characteristics of Hydrogen Charged Vanadium Meta1, M.S. Thesis, lowa State University, 1967 .

18. Neville, A. M. and Kennedy, J. B., "Basic Statistical Methods for Engineers and Scientists," International Textbook Company, Scranton, Pa., 1964, pp 163, 171-198.

19. Lewthwaite, G. W. and Smith, R. T., Brit. J. App1. Phys. $18,1012-1016$ (1967). 


\section{I. ACKNOWLEDGEMENTS}

I would like to take this opportunity to thank ail who have contributed their efforts to this investigation. Special thanks are extended to:

Dr. Tom Scott, who instigated, sustained, and guided this investigation, and who gave generously during preparation of this manuscript;

Dr. C. R. Mischke, for assistance in computer programming, data analysis, and in maintaining perspective in this research effort;

Dr. A. Henkin, for assisting in evaluation of the test apparatus and of this investigation;

C. V. Owen, who supplied helpful knowledge concerning materials processing;

Lester Reed, for his ever-present sense of humor, and for his willing assistance in sample preparation, equipment design, and equipment assembly;

Miss Verna Thompson, for excellent typing service and assistance in properly executing the assembly of this thesis;

My wife, Lois, for continuous emotional and financial support during the pursuit of this degree. 
VIII. APPENDIX A. FIGURES 

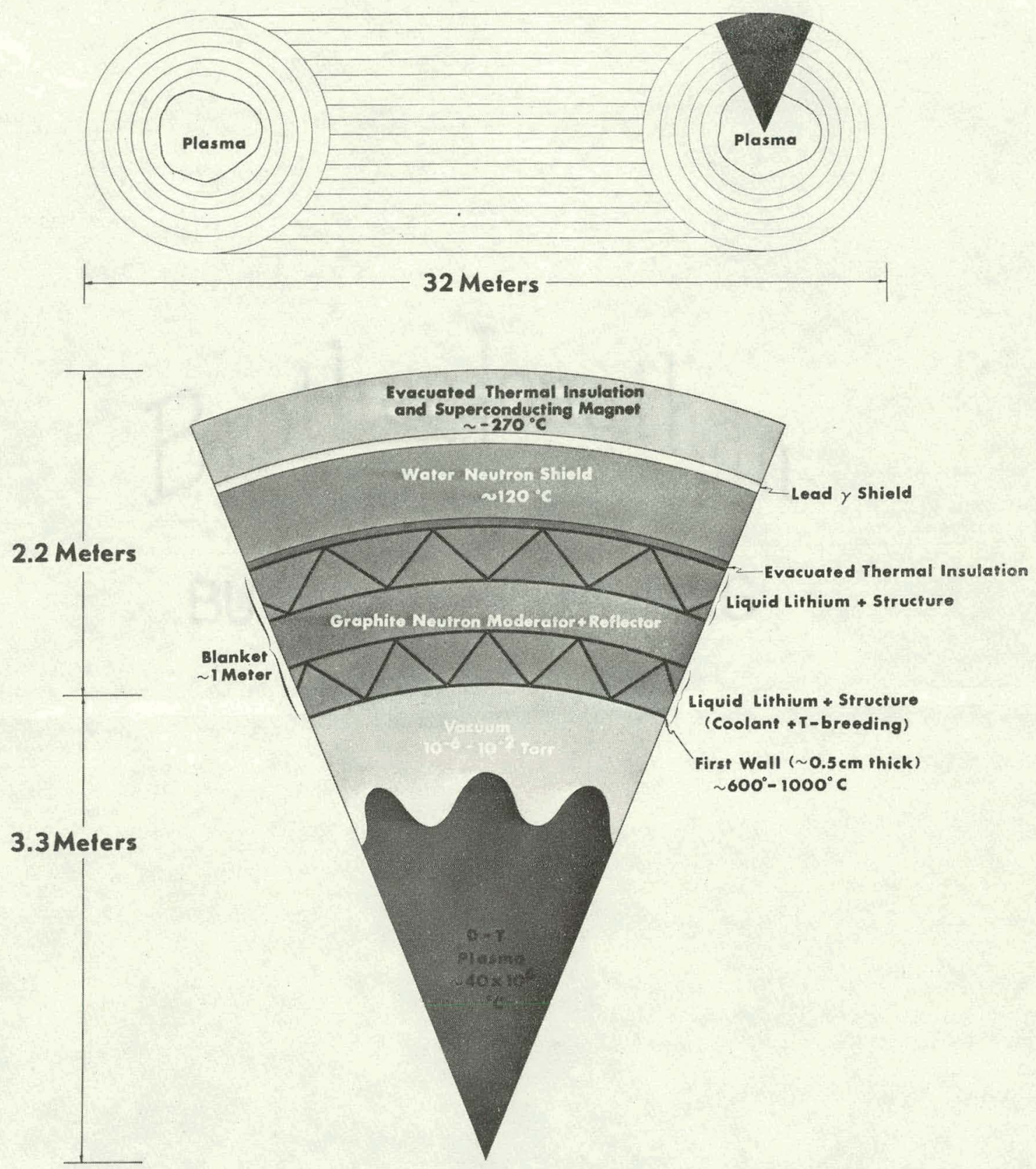

CROSS-SECTION OF A CONCEPTUAL CTR CORE DESIGN

Fig. 1. A conceptual CTR core cross-section after Fraas and Postma (1) 


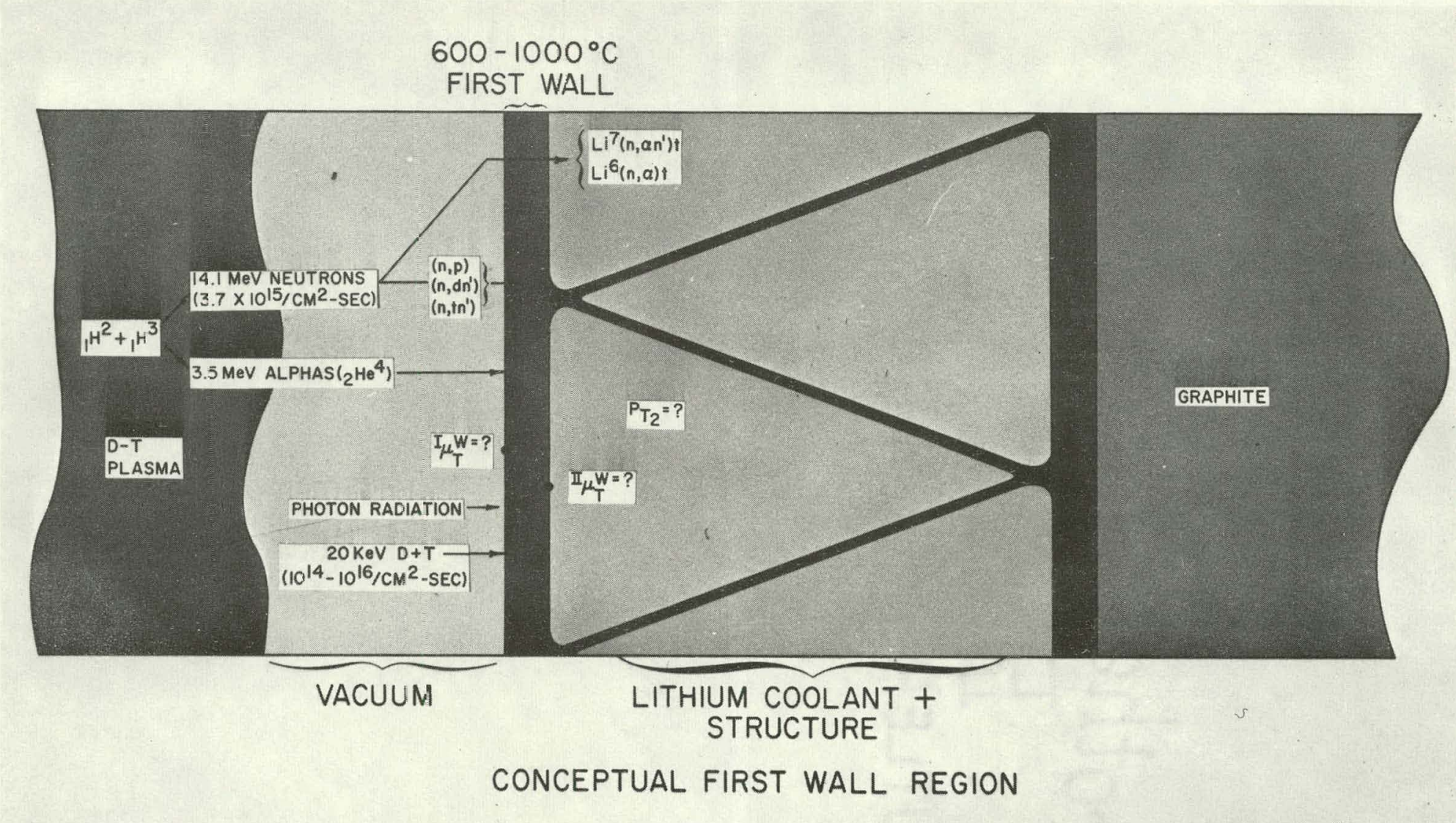

Fig. 2. An enlarged view of the first wall region of the conceptual CTR core illustrated in Figure $I$ showing anticipated environmental conditions 


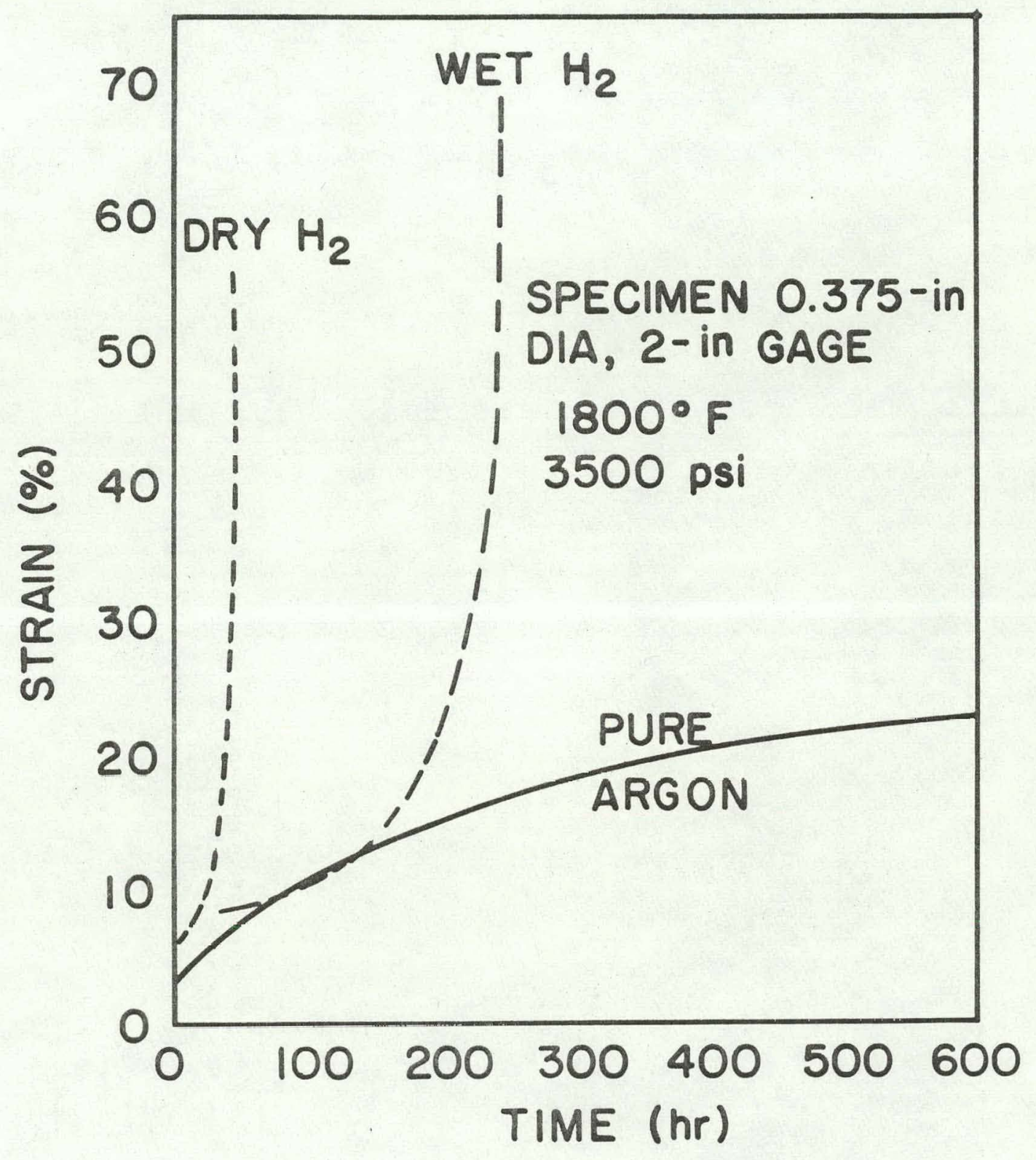

Fig. 3. Experimental results from McCoy and Douglas (15) showing the effect of a hydrogen environment on creep of niobium 


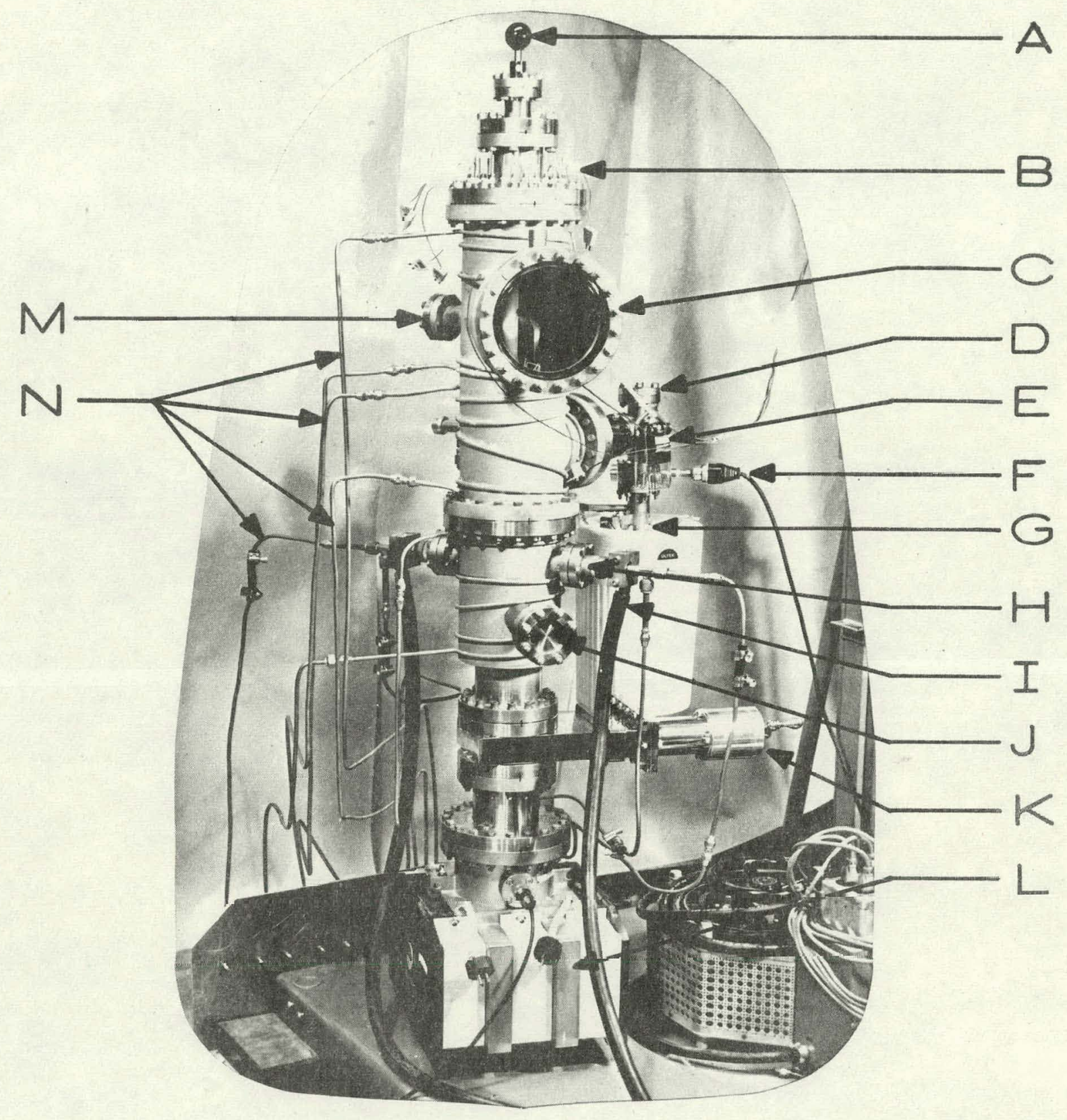

Fig. 4. Overall view of creep test apparatus showing major components. Refer to key on following page 


\section{Key for Figures 4 and 5}
A - Handle of vacuum-tight (bellows-type) translational
motion feedthrough for raising and lowering samples
B - Electrically-insulated feedthroughs for thermocouples
C - Viewport
D - All-metal valve to isolate sorption (roughing) pump from system
E - Bayard-Alpert type ion vacuum gage
F - Thermocouple-type vacuum gage
G - Sorption pump
H - High current, water-cooled electrical feedthrough for furnace element power
I - \#4-0 electrica1 cable for furnace power
$J$ - Location of Titanium Sublimator Pump
K - Gate valve to isolate ion pump from system for hydrogen runs and loading
L - $100 \mathrm{~L} / \mathrm{S}$ ion pump
M - Port for residual gas analyser head
$\mathrm{N}$ - Water lines for cooling test apparatus
0 - Molybdenum sheet stock rolled into cylinder to provide thermal shielding in radial direction
$P$ - Tungsten support rods and electrical conductors for tungsten mesh furnace elements
Q - Tungsten mesh furnace element (only one is shown: the other portion of the element is cut away)
$R$ - Main support rod connecting samples to plunger " $A$ "
$S$ - Portion of internal "cage" 

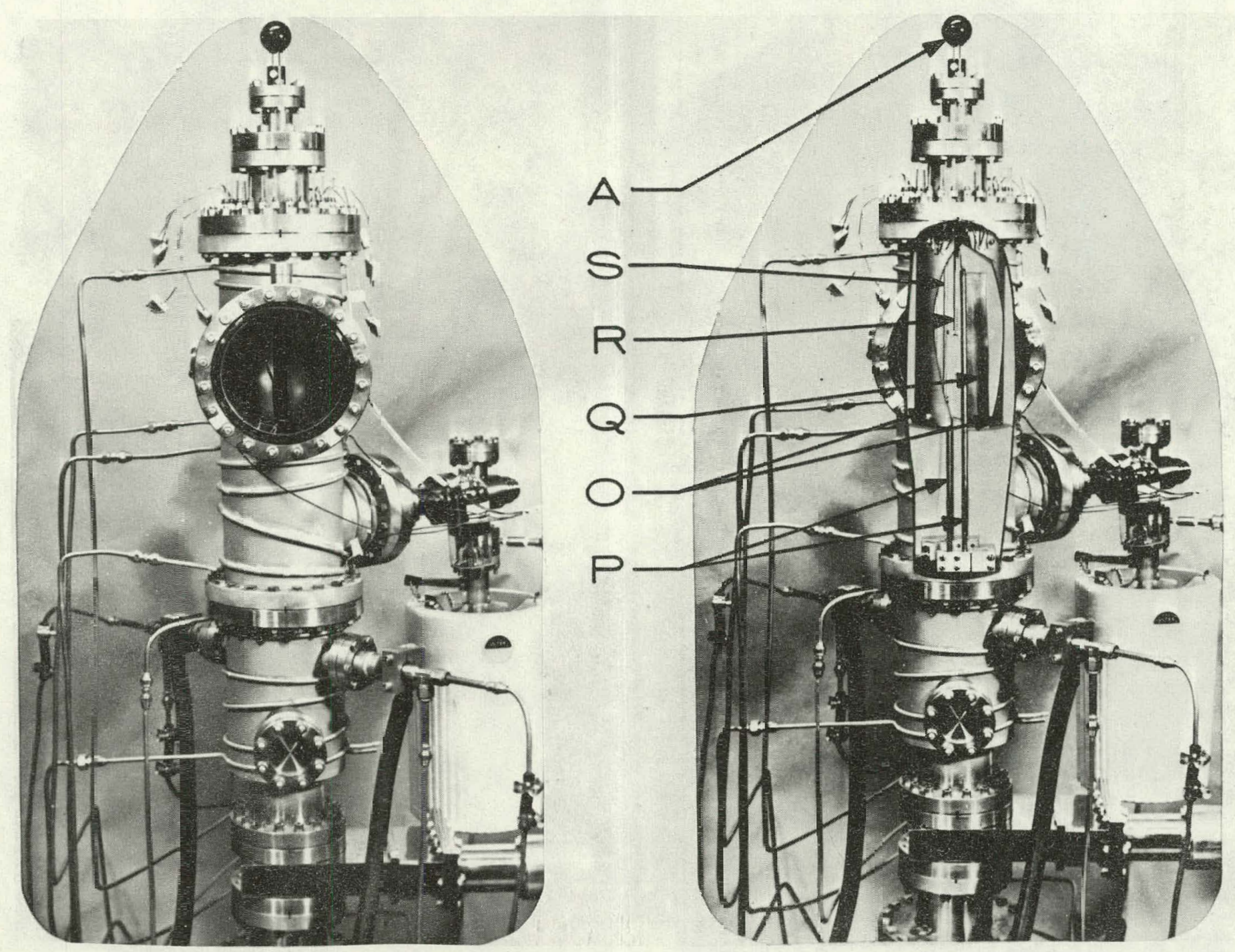

Fig. 5. Test epparatus. (a) Front view of test apparatus; (b) cutaway view of (a). Refer to key on previous page 


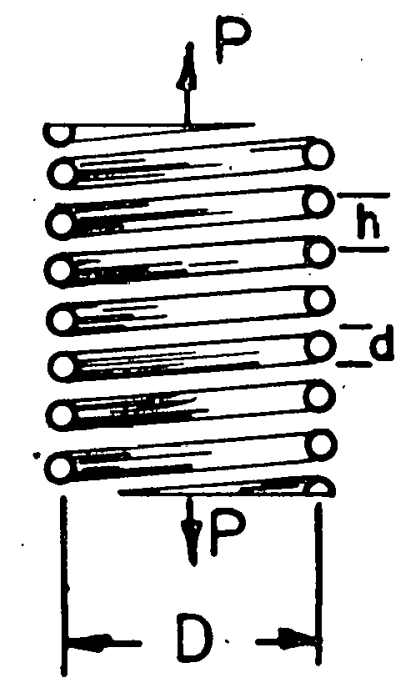

(a)
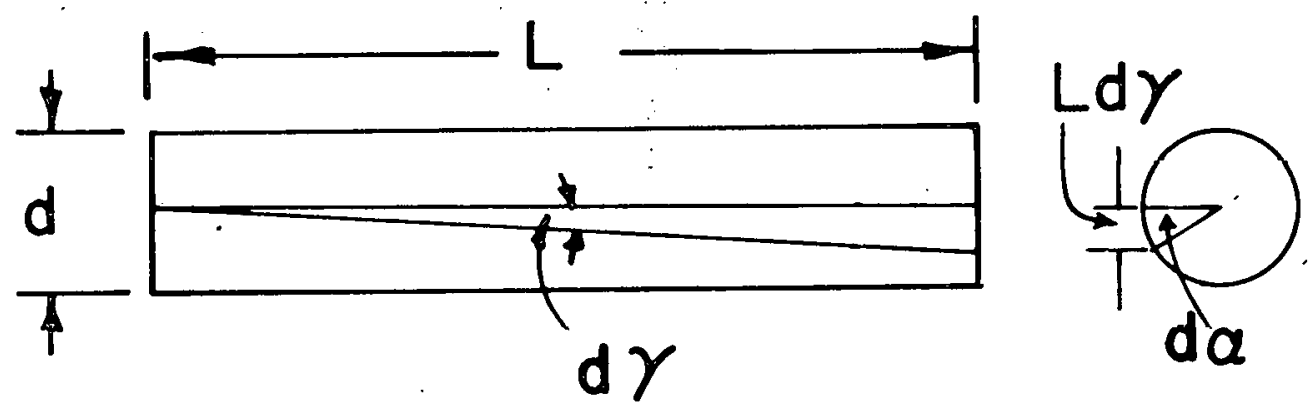

(b)

Fig. 6. Sketch of a helical spring (a), and a wire of circular cross-section under torsional loading condition (b); used in derivation of expression which relates sample elongation to shear strain 


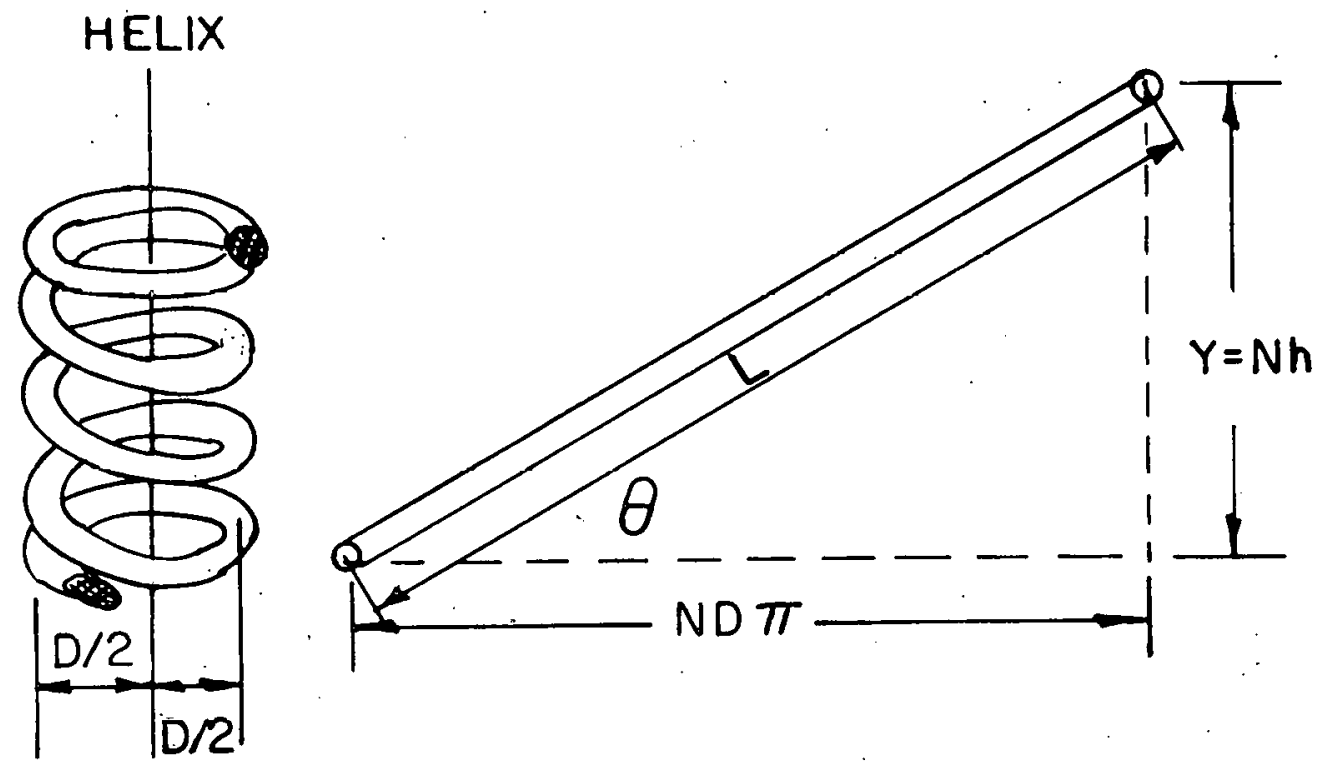

Fig. 7. Sketch of helical spring in coiled and in uncoiled condition; used in derivation of expression which relates sample elongation to shear strain 


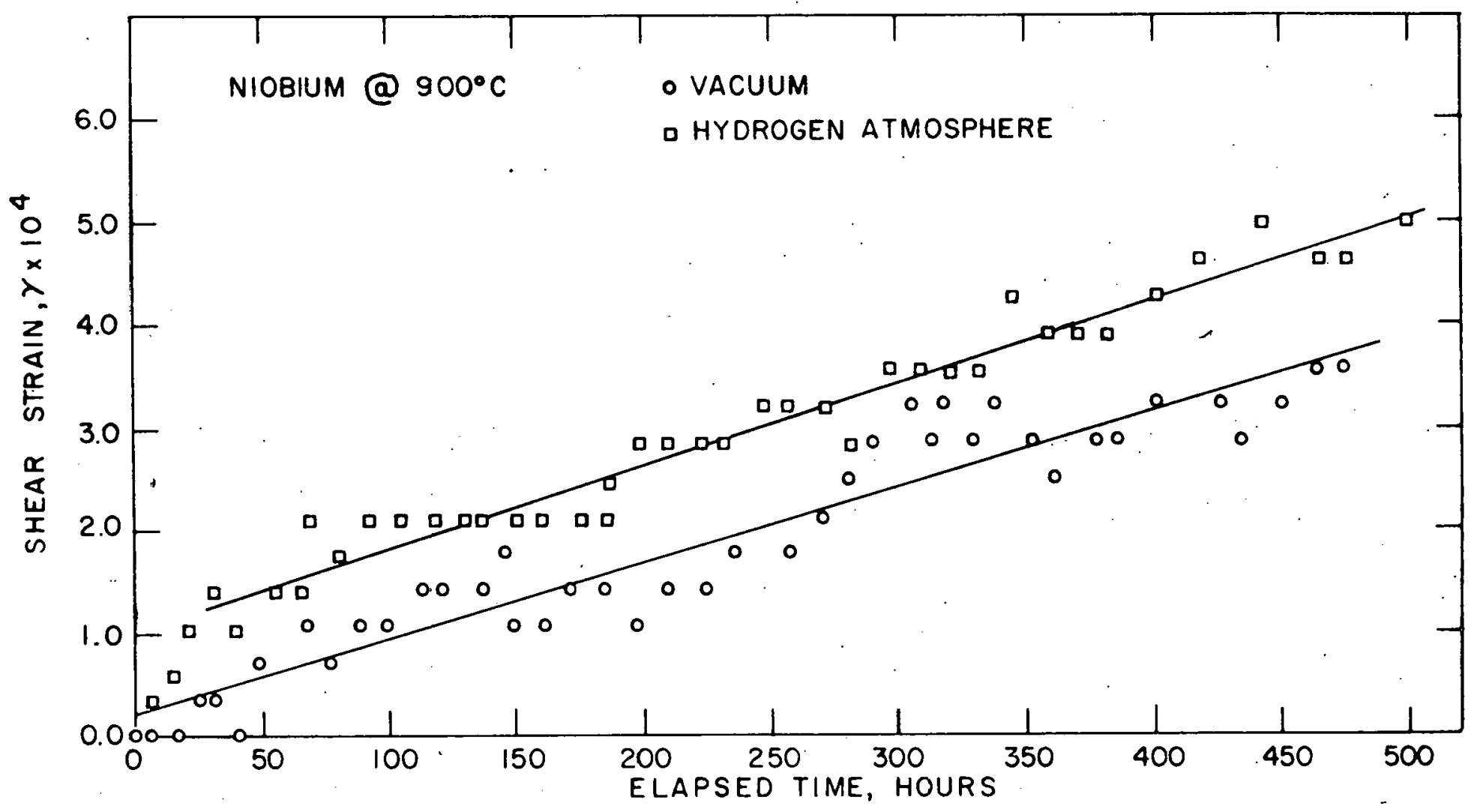

Fig. 8. Shear strain versus time for niobium metal at $900^{\circ} \mathrm{C}$ in hydrogen and in dynamic vacuum 


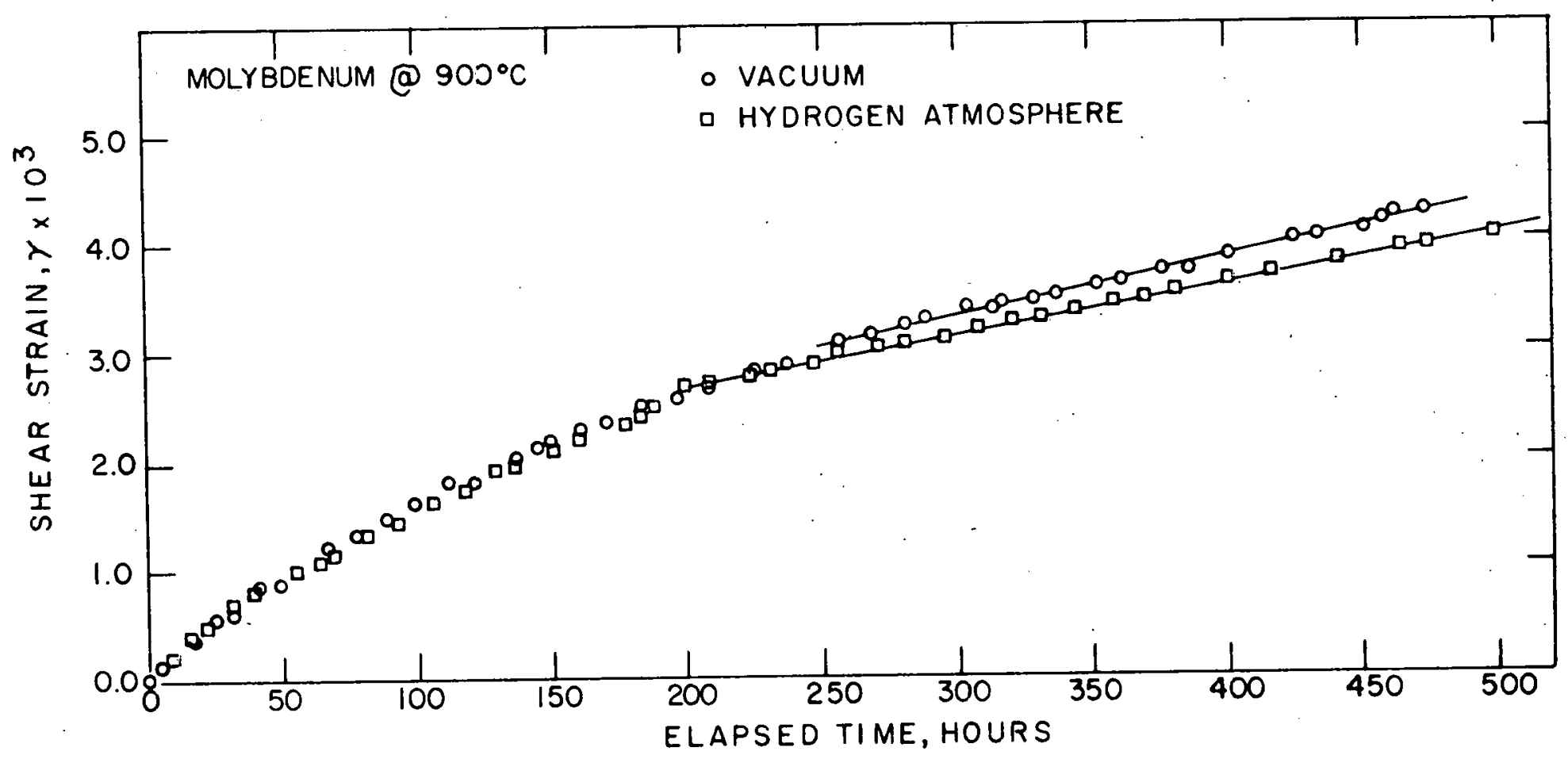

i

Fig. 9. Shear strain versus time for molybdenum metal at $900^{\circ} \mathrm{C}$ in hydrogen and in dynamic vacuum 


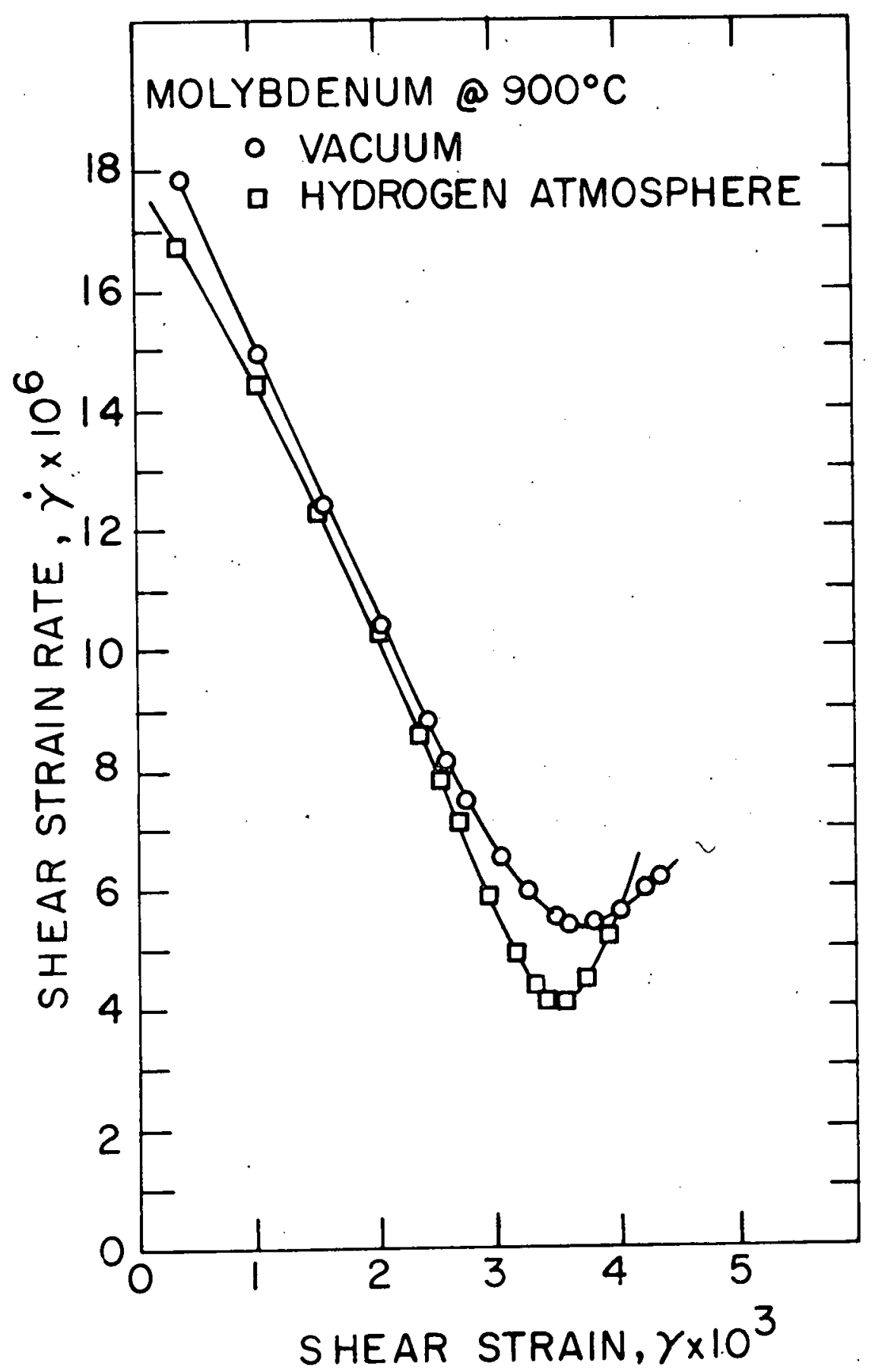

Fig. 10. Shear strain rate versus shear strain for molybdenum metal at $900^{\circ} \mathrm{C}$ in hydrogen and in dynamic vacuum 


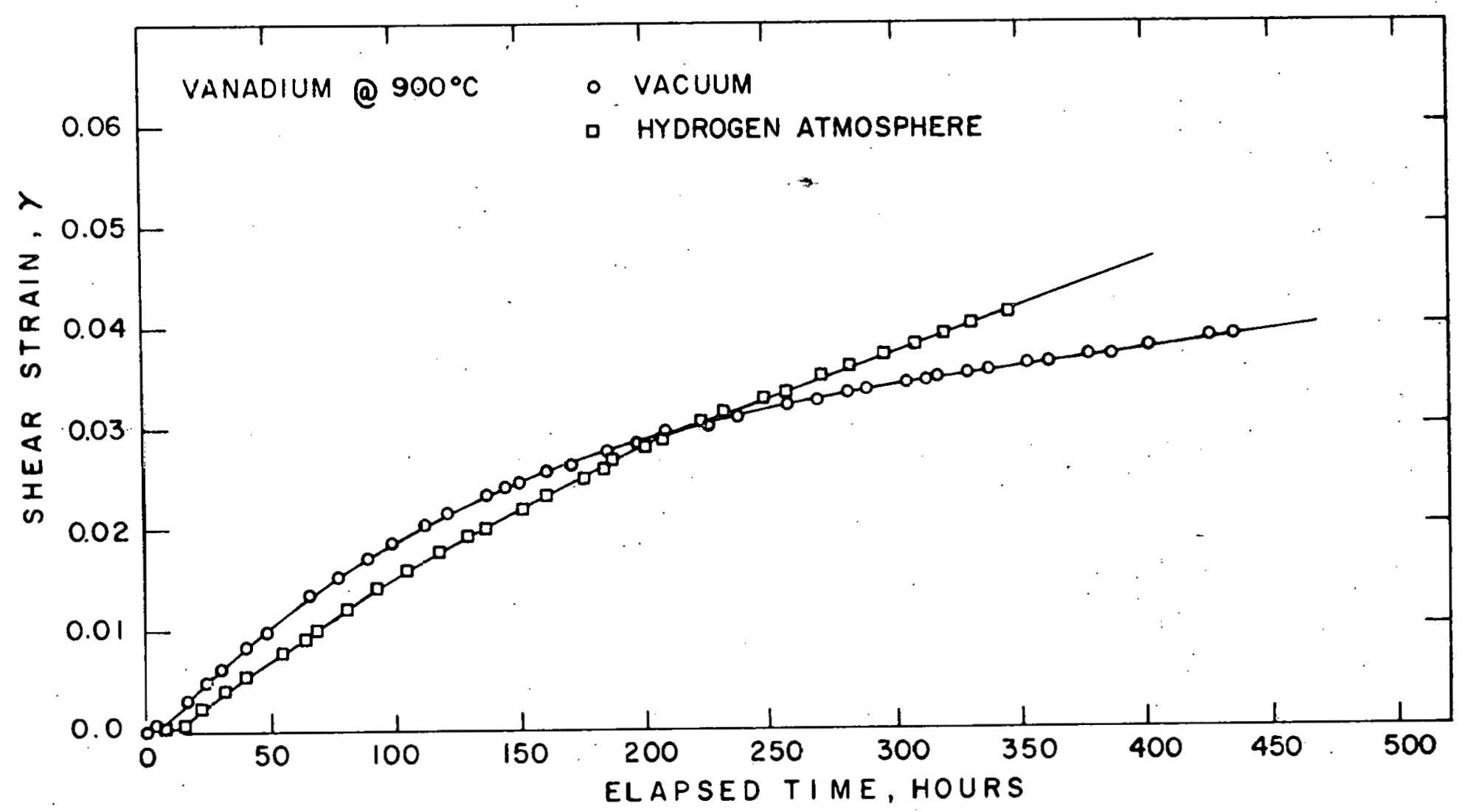

Fig. 11. Shear strain versus time for vanadium metal at $900^{\circ} \mathrm{C}$ in hydrogen and in dynamic vacuum 


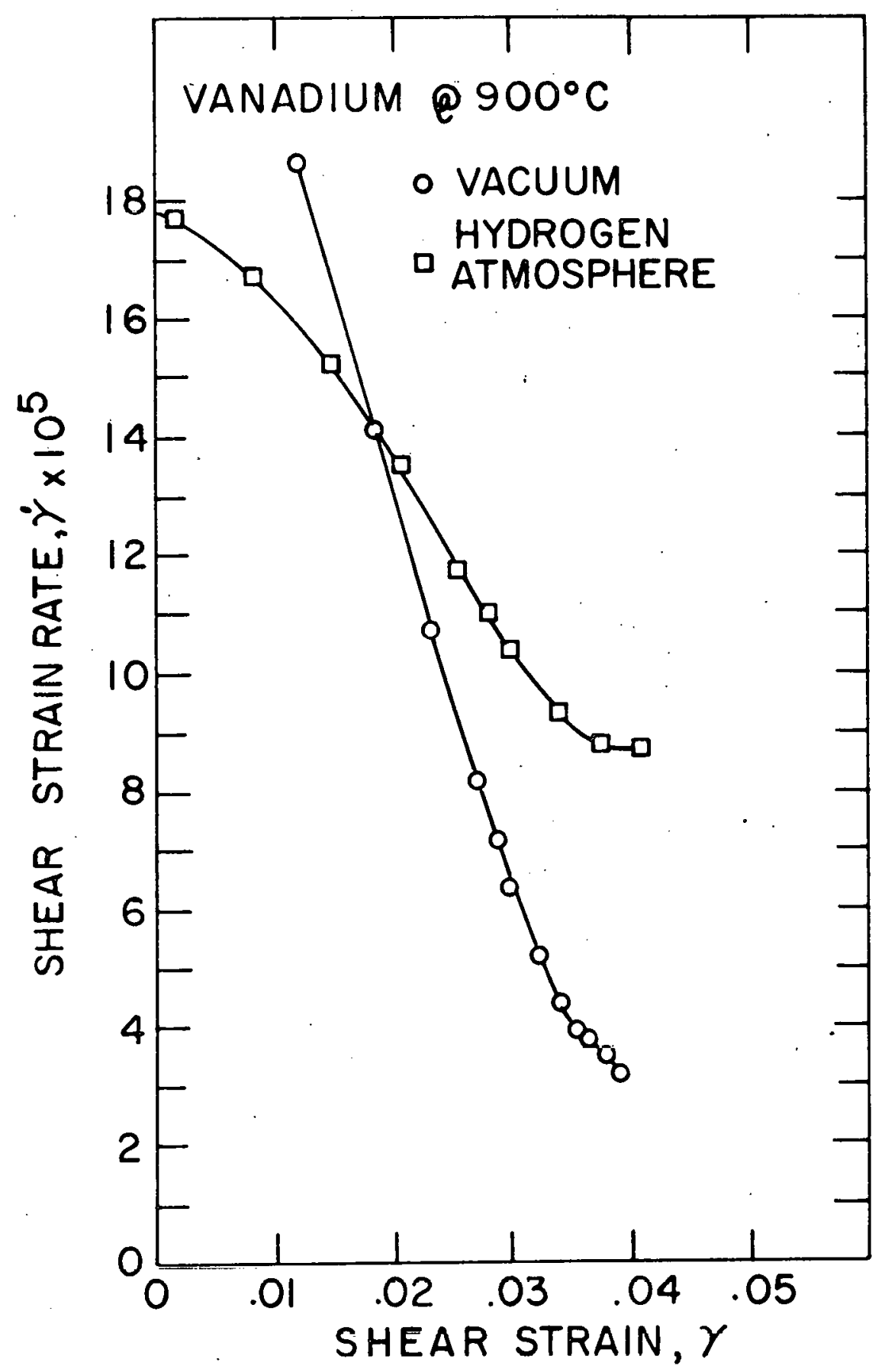

Fig. 12. Shear strain rate versus shear strain for vanadium metal at $900^{\circ} \mathrm{C}$ in hydrogen and in dynamic vacuum 
IX. APPENDIX B. RAW AND PROCESSED

NUMERICAL DATA 


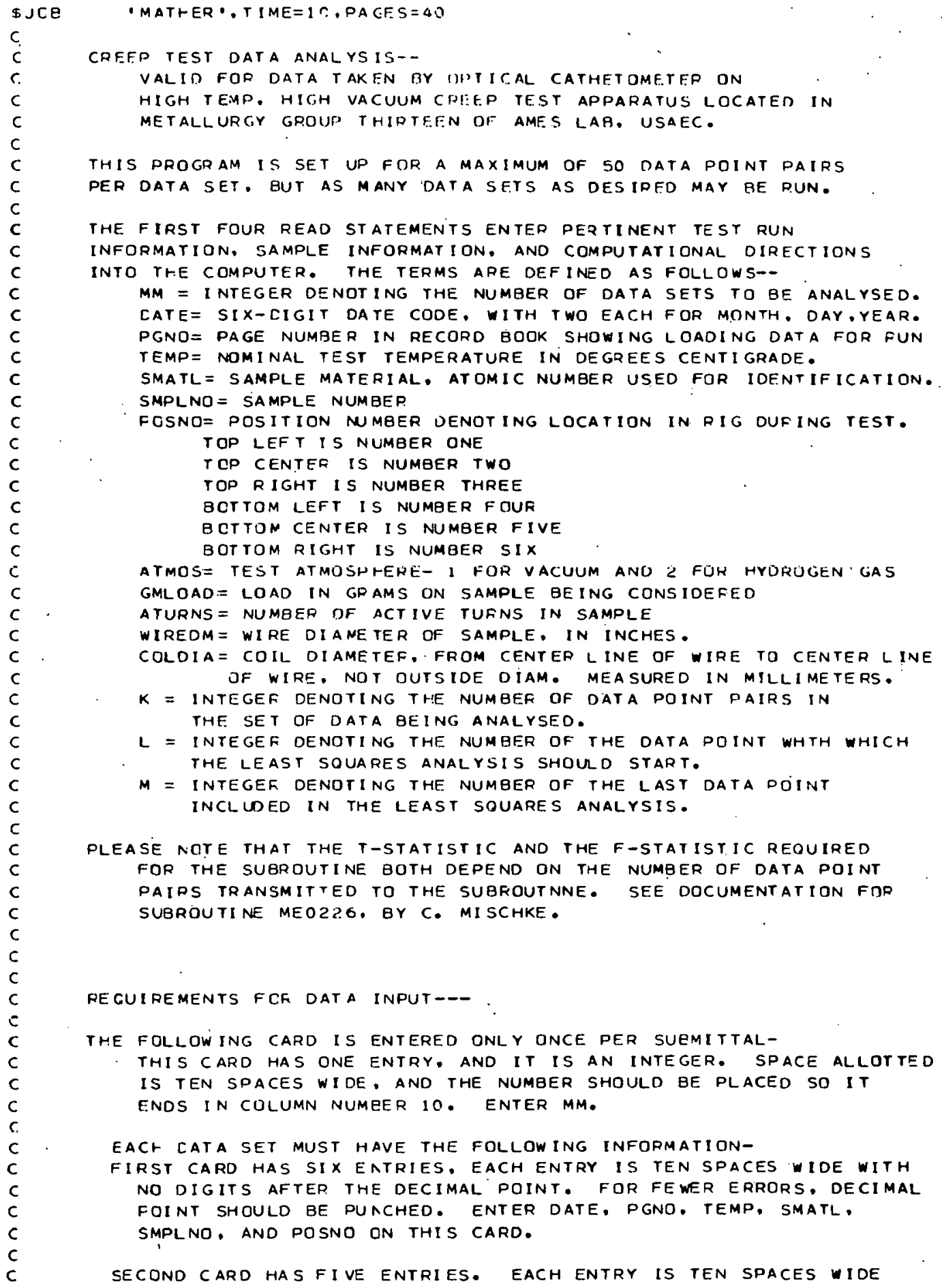




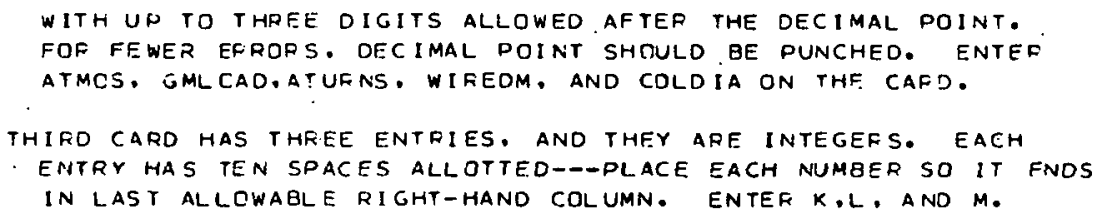

THE FIFTH AND ALL SUCCESSIVE CAROS haVE THFEE ENTEIES. EaCH ENTRY IS TEN SPACES WIDE WITH UP TO THREE DIJITS. ALLOWED AFTER THE DECIMAL. FOR FEWER ERROQRS. PUNCH THF DECIMAL POINTT. ENTEF ELTIME. YUFPCS. BOTPGS.

ELTIME IS THE EL APSED TIME FROM STAFT OF TEST TO THF. READING DF THE OATA POINT IN OUESTION TOPPOS IS THE CATHETOMETER REAOING OF THE POSITICN OF THE TOP OF THE SAMPLE.

BOTPOS IS THE CATHETOMF.TER READING OF THE DOSITION OF THE BOTTOM OF THE SAMPLE.

DIMENSION $\times(50), Y(5 C), B 7(50), B B(50), 89(50), 810(50), 811(50)$

1 B12(5C), 316(50),B17(50), FLTIME(50), TOPPOS(5C), BOTPOS(50).

2 CLNGTH (50), DELTA(50), TEFMS (50), ADG3 (5A). STRAIN(50)

$c$

CONSTANTS ARF AS FDLLDUS

$P I=3.1415927$

$\mathrm{HO}=1 \cdot 4$

FEAD (5.19) MM

19 FOFMAT( 110 )

DO $E S L L=1, M M$

REAO(5.1O) DATE. PGNO.TEMP. SMATL.SMPLNO, POSNO, ATMOS, GILLOAD.

1 ATUPAS. IFEOM. COLDIA

16 FORMAT(GFIC.CISF 10.3$)$

WI FD I $A=W I R E D M * 5.4$

CDATIC:=COLCI A/WIRDIA

$C K=(4 . * C F A T I O-1) /.(4 . * C F A T I D-4)+.(.615 / C P A T I O)$

READ $(5,11) \quad K \cdot L, M$

11 FORMAT(3110)

FEAD $(5,13)$ TSTAT,FSTAT

13 FOFMAT( $2 F 1$ C. 4) 


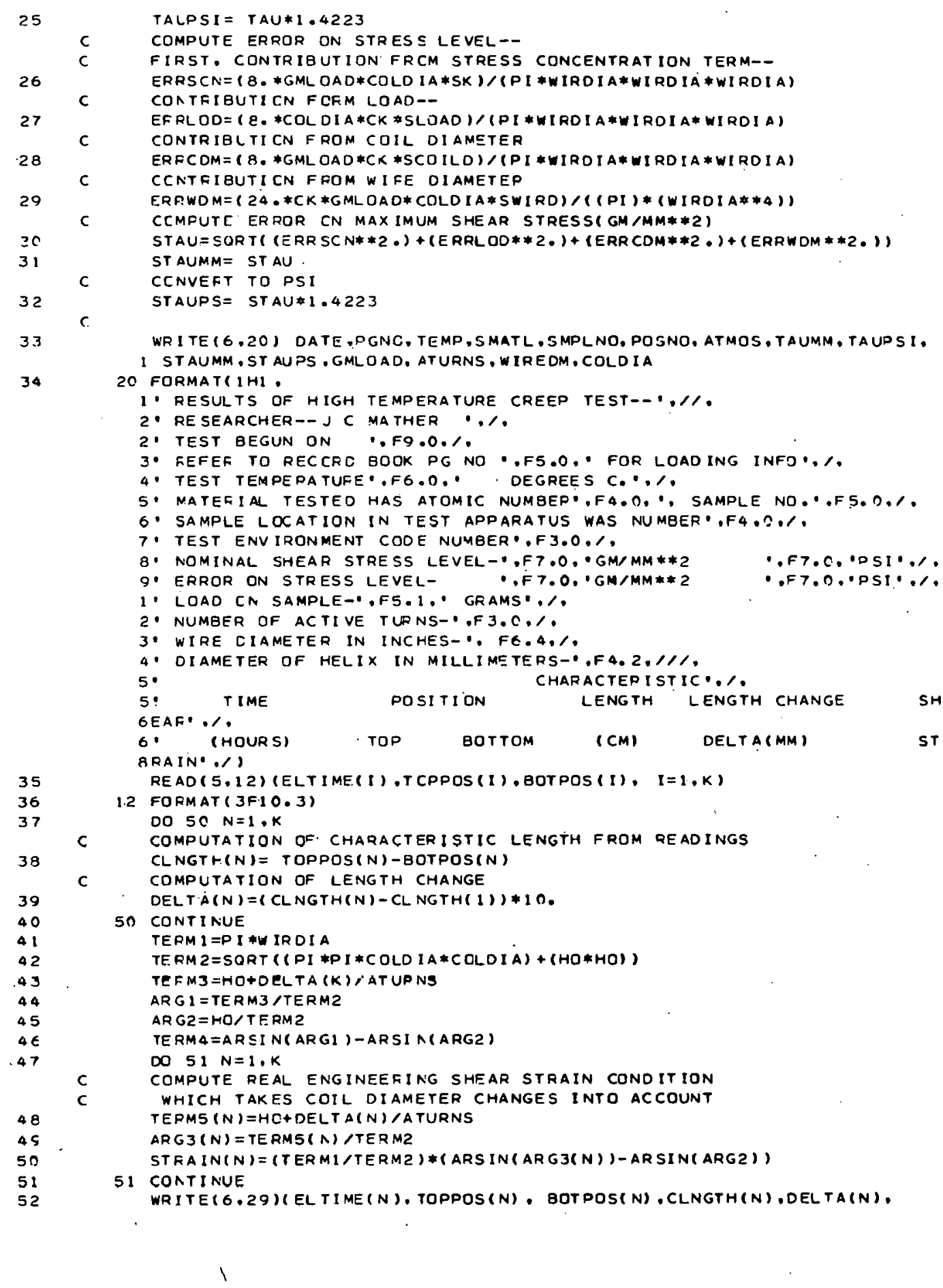


ISTRAIN(N), N=1,K)

29 FORMAT (F11,3,3F1C,3,F1 $2.3, E_{1} 5.4$ )

$K K=M+1-L$

DO $54 N=1, K K$

$X(N)=E L Y I N E(N+L-1)$

$Y(N)=\operatorname{STRA} I N(N+L-1)$

c

54 CONTINUE

COMPUTATION OF MAXIMUM FRROR ON STRAIN--

TO PE USED IN SUBROUTINE ME2 $26 R$

PRTLI IS THE PARTIAL DERIVATIVE OF STRAIN WITH RESPECT YO THE NUMBER DF ACTIVE TURNS

PFTL $1=($ TCRMI *DELTA $(K)) /($ (ATURNS *ATURNS*TERMZ*TEF M 2$) *(S O R T(I .-A R G 1$ * (APGI)

$c$

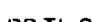

PRTL2=TE THE PAFTIAL DERTVATIVE OF STRAIN WITH PESPECT

PRTL 3 IS THE PARTIAL DFRIVATIVE OF STRAIN WITH RESPECT TO

WIFE CIAMETEF

PR TL $3=P$ I *TERM4 /TERM2.

FFTL4 IS THE PARTIAL DERIVATIVE OF STRAIN WITH RESPECT TO

COIL CIAMETER

$A A 1=T E R M 1 * T E R M 4 * P I * P 1 * C$ CLDIA/TEPM $2 * 3$

$A A 2=P I \# P I * C O L D$ [A *TERM $3 /(1$ TERM $2 * 3) * S O R T(1 .-A R G 1 * A R G 1)$

$A A 3=H C$ $P I * P I * C O L D I A /((T E F M 2 * * 3) * S O R T(1$-ARG *APG $))$

PRTL $Q=(T E R M 1 / T E R M 2) *(A A 3-A A 2)-A A 1$

FFTLS IS THE PARTIAL. DERIVAT IVE OF STRAIN WITH RESHFCT TO

INITIAL SDACING GFTWEEN TURNS OF THE COIL.

$B B 1=T E F N 1 * T E R M 4 * H O / Y F R M 2 * 3$

$B B E=T E R M 3 * H O /((T C R M 2 * 3) * S O P T(1 .-A P G 1 * A R G 1)$

EB $3=1 . /(T E R M 2 * S O R T(1$. ARG $1 * A R G 1)$ )

BB $4=H O * H O /((T E P M 2 * 3) * \operatorname{SORT}(1 .-A R G 2 * A R G 2))$

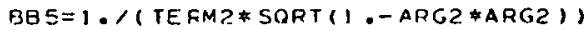

PRTL $5=($ TERMI/TEFM2)*(B3:3-BB2+BB4-BB5) - BB 1

SGAMMA $=S O R T((P R T L 1 * S N) * 2+(P R T L 2 * S Y) * 2 *(P Q T L 3 * S W 1 R D) * 2 *(P=T$ $1 L 4 * S(O I L D) * 2$ * (PRTLS*SHO)*\#2)

CALL ME226F(1,KK.X.Y.TSTAT,FSTAT,SGAMMA,B1,B2, E3,BA, BS, B6, G7, B8,

$1 B 9.81 C . B 11.812 .813 .814 .015 . B 16.817)$

66. CONTINUE

STOP

END

SUEROUTINE ME226RIMUN, N,X,Y, TSTAT,FSTAT,FF, A,B, XSAF, YSAE, SA, SB, UP,

I DOWN,CUP, COOWN,FUP, FD CWN,R,SYX, SYBARX . SYI . SFUT)

STRAICHT LINE RE GRESSIIN OF $Y$ ON $X$ * $Y=A+B * X$

$M E 226 R(11,12, A 3, A 4, A 5, A 6, A 7, B 1,82, B 3,84, B 5,86,87,88, B 9.810 . B 11 . B 12$.

1 B $13,814, B 15, B 16, B 171$

PERF CRNS A LINEAR LEAST SOUAPES REGDESSION OF $Y$ ON $X$. $0 O R$ THE FOUTINE ACCEOTS MONITOR PRINT SIGNAL. NUMBER OF DATA PAIRS. COLUMNDCCBB VECTORS OF DATA. T-STATISTIC AND F-STATISTIC FOF CONFIDENCE BOUNDS. AONO AND VALUE OF UNCERTAINTY FOR DRDINATES.

THE ROUTINE RE TURNS INTERCEPT ANO SLIJPE OF REGRESSION LINE, DATA CENTPOID COOPDINATFS, STANDAFD DEVIATION OF INTERCEPT AND SLOPE, UFPEP AND LOWEF CONFIDENCE BOUNOS DOINT-BY-POINT. UPPER AND LOWER CONFIOENCE BOUNDS FOR THE LINE-AS-A-WHOLE.

CCNFICENCE BOUNDS FOP A FUTUPE POINT, COFPELATION COEFFICIENT

STANDARD UEVIATICN OF $Y$ ON $X$, YBAR ON $X$, YBAPI AND FUTURE 
SEE NATIONAL BUREAU CF STANDARDS SPECIAL VOLUME 300. PAGE 20 A ETAL 0016 CALLING PROGPAN REOUIREMENTS

frCVIOE THE EQUivalent to the following deQ aration:

DINENSION A3 (I2).A4( $(2) . B 7(12) .88(12) .89(12) .810(12) .811(12) .812(12)$. On23 Q16(12).B17(12)

CALL LIST ARGUNENTS

$20 \mathrm{C} 23$

I I = M MEITOR AND PLOTIING TABULATION DOES NOT PRINT

$=1$ MINITIR ANO PLOTTING TABULATION PRINTS ON SEPARATE PAGC OOZB

$12=$ NUMBEF OF DATA DOINT PAIRS

A $3=$ CCLUMN VECTOR OFDATA $X$-COORDINATES

$A Q=C O L U M N$ VECTOR OF DATA $Y$-COORDINATES

AG =F-STATISTIC FI2 I2-2I FOF I-ALPHA. ALPHA = SIGNIFICANCE LEVEL OF BOUND

A7 = UNCERTALNTY VALUE FOR OATA Y-COORDINATES

DI =ORDINATE INTERCEPT OF REGRESSION LINE

TONE 2035

GL $=5 L C P E$ OF PEGFESSION LINE

$B 3=X$-COORDINATE OF DATA CENTFOID

$B A=Y-$ COORO INATE OF DATA CENTPOIO

B5=STANOARD DEVIATION CF OROINATE INTERCEPT OF REGRESSION LINE DO

E6 =STANDARO OEVIATION OF SLOPE OF REGRESSION LINE

$87=$ COLUMN VECTOF UPPER CONFIDFNCE BDUND POINT-BY-POINT

SR=COLUMN VECTOF LOWER CONFIDENCE BOUND POINT-BY-POINT

B9=CCLUMN VECTOF UPPEF CONFIDENCE BOUND LINE-AS-A-WHDLE

B1O=COLUMN VECTOR LOWER CONFIDENCF. ROUND LINE-AS-A-WHOLE. TCAA

Q11=COLUMN VECTOR UPPER CONFIDENCE OOUND FOF FUTUPE POINT

BI $2=$ COLUMN VECTOR LOWEO CONFIOENCE MOUND FOF FUTURE DOINT ONA

BI $3=$ COPRELAT.ION COFFFI CIENT

BI $4=$ STANDARO DEVIATION $Y$ ON $X$. SYX

BI $s=S T A N D A F D$ OEVIATION YBAP ON $X$. SYGARX

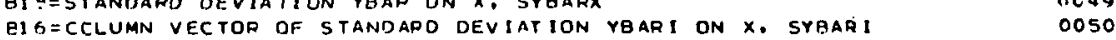

0047

0040

B17=COLUMN VECTOR TF STANIDARN DEVIATION YFUTURE ON $X$. SYFUT

0059

$\begin{array}{ll}\text { NONE } & 2055\end{array}$

0056
0057

DIMENSICN $X(1), Y(1), \operatorname{UP}(1)$, DOWN $(1), \operatorname{CUP}(1), \operatorname{CDOWN}(1), F U P(1), F D O W N(1)$, DOSB

1 STI(1), SFUT(1) $\quad$ DOOSB

\begin{tabular}{rr} 
GOTO 103 & 0050 \\
\hline
\end{tabular}

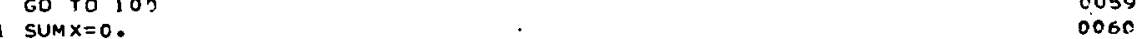

SUM $X=0$.

$\operatorname{siJMY}=1$.

SUM $x \times=0$.

SUMYY $=0$

SUMXY $=0$.

$\operatorname{SUM} 1=0$.

SUM $=0$.

SUM $3=0$.

SUNA $=0$.

$\infty \quad I=1 \cdot N$

SUMX $=\operatorname{SUM} X+X(I)$

SUMY $=$ SUM $Y+Y(I)$

SUAXXXIUA $X X+X(1) \neq X(1$

0060

0062

0063

0064

0065

$0<66$

0466
$n 067$

3067

0008

0069

0C70

0071
0072 
2 CONTINUE

XBAR $=$ SUM $X / F L O A T(N)$

YBAF = SUMY $/$ FLOAT (N).

ANUM $=$ SUM $X X *$ SUMY-SUMX $*$ SUM $X Y$

BNUM = FLOAT $(N) *$ SUMXY - SU NX *SUMY

OE NOM $=F L O A T(N) *$ SUM $X X-\operatorname{SLMX} * \operatorname{SUMX}$

IF(DENCM.NE.0.) GO TO 1070

WOITE(6.106)

1 CG FORMAT: * H+ +

I. INTERCEPT AND SLOPE UNDETERMINANT CHECK DATA'! DOB

$\triangle=A N L M / D E N O M$

$B=B N U M / D E N O M$

DO $3 \quad I=I \cdot N$

SUM $1=\operatorname{SUM} 1+(X(I)-X S A R) *(X(1)-X B A R)$

SUM2 $=S U M 2+(Y(I)-Y B A R) *(Y(I)-Y B A R)$

SUM $3=\operatorname{SUM} 3+(X(1)-X B A R) *(Y(I)-Y B A R)$

SUMA $=$ SUMA+(Y $(1)-A-B * X(1)) * * 2$

3 CONTINUE

IF (SUM: .NE .O., GU TO 1 :8

WRITE $(6,107) \times(1)$ IEFFOR $=1$

IF (SUM2 NE. 0.1$)$ GO TO 110 WRITE(6.109)Y(1)

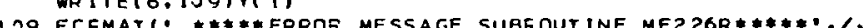
ALL Y-OBSERVATIONS SAME.".615.7.'. CHECK DATA'; IEFFOA $=1$

110. IF (IERROR. NE.C) RETURN

$P=S O R T(($ SUM2-SUMA)/SUMZ)

SYX = SORT ( $(S U M 4 / F L D A T(N-2))$ ) RR \#FR)

SYBARX SYX/SORT(FLDAT(N))

$S B=S O R T(\leqslant Y X * S Y X /$ SUMI)

$S 2 A=\$ Y X * S Y X *(1 . / F L O A T(N)+X B A F * X E A R / S U M I)$

$S A=S O R T(S 2 A)$

$A U P=A+T S T A T * S A$

$A L$ OW $=A-T S T$ T T $* S A$

$B U P=B+T S T A T * S B$

ELOW $=E-T S T$ AT $* S B$

YUF $=Y E A F+T S T A T * S Y B A R X$

L. OW = YEAR - TSTAT*SYBARX

DO $4 \quad t=1$, $N$

$Y H A T=A+B * X(I)$

AR G2 = SYX*SYX*(1, /FLOAT $(N)+(X(1)-X B A R) * * 2 / S U M 1)$

$S Y I(I)=S Q R T(A R G 2)$

UP (I) =YHAT +TSTAT \#SYI (I)

DOWN(I) = YHAT - TSTATESYI (1)

CUP(I) =YHATt SOPT (2,*FSTAT) FSYIII)

CDOWN (I) =YHAT- SORT(2, STAT)*SYI(I)

ARG $=\leq Y X * S Y X *(1,+1$ OFLOA $(N)+(X(1)-X B A Q) * 2$ /SUM1

SFUT $(I)=\operatorname{SORT}($ AFG 3$)$

FUP (I) =YHAT+TSTAT *STUT (I)

FOOWN (I) =YHAT-TSTAT*SFUTII)

4 CONTINUE

IF (MCN.EC.O) GC IO 99

WRITEIC, E)

FOFMAT $10,1 \cdot$, 


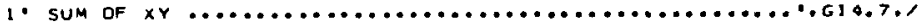

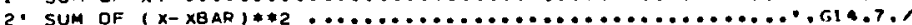

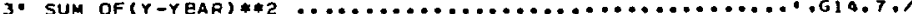

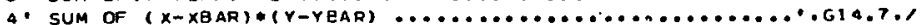

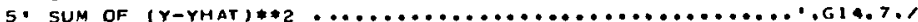

6. UNBLASED ESTIMATOR STANDARD DEVIATION $Y$ ON $x$. SYX .....GIa.7.

7. UNGIASED EST IMATDQ SYBARX ...........................

9. UNBIASED ESTIMATOR OF STANDARO DEY IATION OF A. SA ..... G19.7.

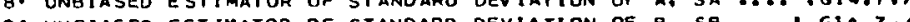

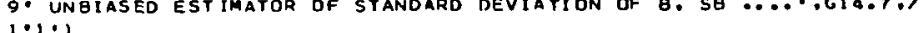
costurn

c ......protect ton.....

IERROR=0

IF (MON.EO.O.OR.MON.EO. A) GU TO 102

WRI TE $(E .101)$ MCN

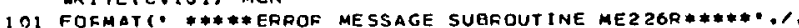
IERFOR=1

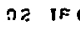

WRITE $(6,103)$ IN

C3 FORMAII: ****ERROR MESSAGE SUBROUTINE MEZ26R*****1,/,

ienasom-1 ARGUMENT $12, \cdots 115, \cdots$ NOT GREATER THAN TWO 1

WRITE 16 . I SSITSTAT.FSTAT

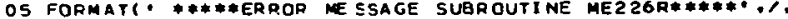
IERROR = 1

105? IF (IERROR.NE.0) RETURN

IEFROR-O

GO TO

END 
HF SULTS OF HIGF TEMPERATURF CRECH TF:'TT--

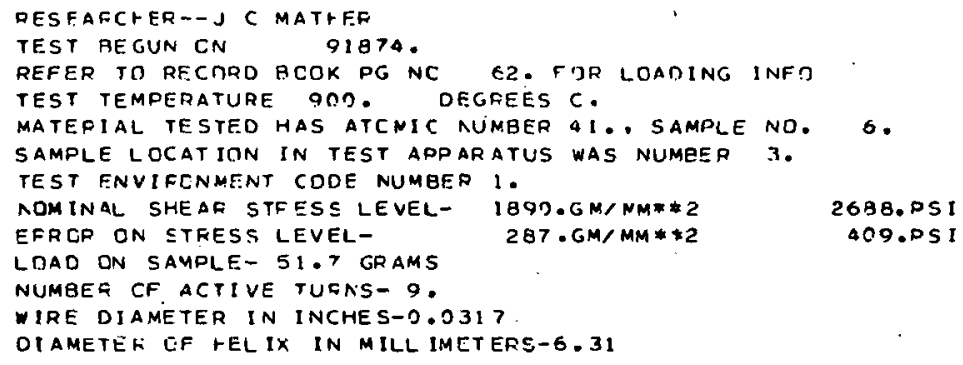

TIM

(HOUFS)

C. 200

.5 .066

17.066

25.330

31.336

41.3 .30

$45.2 E 6$

67.586

77.60 .

89.670

99.330

113.000

121.67 .

$137.2=0$

144.900

$150.0 \mathrm{CC}$

161.200

170.560

195.000

$197.60 \mathrm{C}$

$2 C 9.4 C C$

$225.4 \mathrm{CO}$

237.400

$257.67 ?$

264.670

$24 C .830$

289.670

305.000

$313.5 n 0$

317.830

325.100

337.500

353.330

361.430

377.240

$386.1 \in 0$

421.60 ?

$425.67 c$

$434.32 \mathrm{C}$

$50 . \leqslant 20$

$4 \in 3 . \in C C$

473.500

TOPOSTIION

1.215 .

1. 215

.215

1.220

$1.2 \geq 0$

1.7 .15

1.225

1.233

1.225

1.230

1.230

1.235

1.235

1.235

1.240

1.230

$1.23 n$

.235

1.235

1.230

1. 235

1.235

1.240

1.240

1.245

1.250

1.255

1. 260

.355

1.260

1. 255

1.260

1.255

1.250

.255

1. 255

1.260

. 260

1.255

1.260

1. $2 \in 5$

1. 265

CHARACTERISTIC

BOT THM

$$
\text { LENGTH L }
$$

$$
\text { (CM) }
$$

ENGTH CHANG

$c .000$
$c .006$

1. 215

1. 215

C. 020

c. $00 \mathrm{C}$

1. 215

1. 220

0.000

c. 00 ?

0.000

c.00s

c.0OC

$\mathrm{c} .000$

c.000

C. 000

C. 000

c. 200

c. 000

c. on?

c. con

c. 0.00

C. 000

c.onc

6.000

c.000

c. 002

C. 200

6.000

6.000

1.000

0.000

c. non

0.000

c. 000

c. 500

0.000

6.000

c.000

0.000

c. 000

c. 000

0.000

2.000

c. 000

0.000
1.215

1. 215

1. 230

1. 225

1. $23 n$

1.230

1. 235

1. 235

1. 235

1.240

1.236

1.230

1.235

1. 235

1.230

1. 235

1. 235

1. 240

1. 240

1. 245

1. 250

1. 255

1. 260

1. 255

1.260

1. 255

1. 260

1. 255

1. 250

1. 255

1. 255

1. 260

1. 260

1.255

1. 260

1.265

1. 265
DELTA(MM)

0.000

c.000

0.000

0.050

0.050

0.100

0.150

$0.10 \mathrm{C}$

$0.15 n$

0.150

0.200

0.200

0.200

0.250

$0.15 n$

0.150

$0.2 \mathrm{CC}$

0.210

0.150

$0.2 n 0$

0.203

0.250

$0.25 n$

0.300

0.350

0.400

0.455

c.ano

0.453

0.400

0.450

0.400

0.350

0.400

$0 . a n c$

0.450

0.450

0.400

0.450

0.500

0.5 ?
SHEAR STRAIN

. .0ODE OC 0.0000 or 0.7000 E OO $0.3572 E-34$ $0.3572 E-04$ 0.00CJE 0O $0.7146 E-0$. $0.1072 E-03$ $0.7146 E-04$ $0.1072 E-03$

C.1.072E-02 $0.1429 E-03$ $0.1429 E-03$ 0.142 QE-O.? $0.1786 E-03$

$0.1072 E-03$ $0.1072 E-03$ $.1429 E-03$ $0.1429 E-03$ $0.1072 E-03$

$0.1429 E-03$ $0.1429 E-03$ $0.1786 E-03$ C. $1786 E-03$ C.2144E-03 $0.2501 E-03$ $0.285 B E-03$ $0.3216 E-03$ $0.2858 E-03$ $0.3216 E-03$

$0.2858 E-03$ $0.3216 E-n 3$ $0.2858 E-03$ $0.2501 E-03$ $0.2859 E-0.3$

$0.285 B E-03$ C. $3216 E-03$ $0.3216 \mathrm{E}-03$ $0.2858 E-03$ $0.3216 E-03$ $0.3573 E-03$
$0.3573 E-03$ 
RESULTS OF HIGH TEMPERATURE CGEEP TEST--

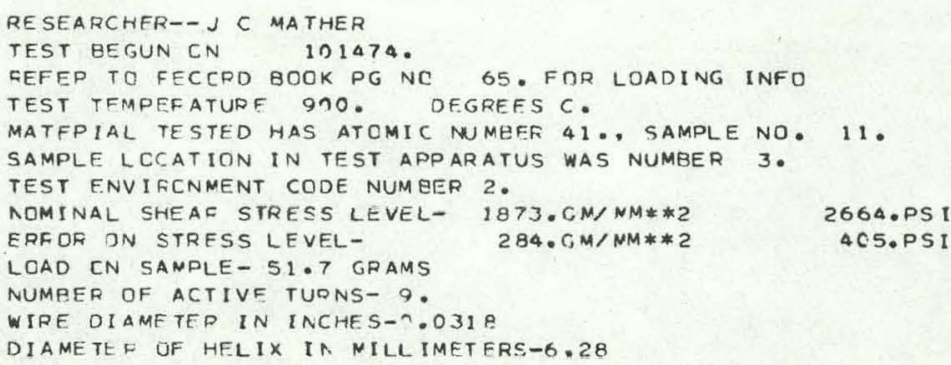

\begin{tabular}{|c|c|c|c|c|c|}
\hline & & & NCT EP & & \\
\hline TIME. & PO & ON & LENGTH & LENGTH CHANGF & SHEAR \\
\hline (HOURS) & $T O P$ & BOT TOM & (CM) & DELTA(MM) & STFAIN \\
\hline$C .00 \mathrm{C}$ & 1.181 & c. $\cos$ & 1.181 & $0.00 \mathrm{C}$ & $0.0000 E$ OO \\
\hline 7.530 & 1.185 & 0.000 & 1.185 & 0.040 & $0.2889 E-04$ \\
\hline $15.53 \mathrm{C}$ & 1.190 & 0.000 & 1.190 & 0.090 & $0.6498 E-04$ \\
\hline $21.67 C$ & 1.195 & 0.200 & 1.195 & C.14C & $0.1 \times 11 E-n 3$ \\
\hline 31.750 & 1.200 & 0.000 & 1.200 & 0.190 & $0.1372 E-03$ \\
\hline 40.000 & 1.195 & 0.000 & 1.195 & 0.140 & C.1011F-n3 \\
\hline 55.600 & $1.20 ?$ & $0.30 n$ & 1.200 & 0.190 & $5.1372 F-0.3$ \\
\hline $64.75 C$ & 1.200 & $c .000$ & $1.20 \mathrm{C}$ & n.19n & $0.1372 E-03$ \\
\hline 69.670 & 1.210 & 0.000 & 1.210 & 0.290 & $0.2 C 94 E-03$ \\
\hline $8 \mathrm{C} .7 \mathrm{CC}$ & 1.205 & C. $00 \mathrm{C}$ & 1.205 & $n .240$ & $0.1733 E-03$ \\
\hline 92.700 & 1.210 & 6.000 & 1.210 & 0.290 & $0.2094 E-03$ \\
\hline $105.3 \mathrm{CC}$ & 1. $21 n$ & 0.000 & 1.210 & 0.290 & $2.2094 E-03$ \\
\hline $118 \cdot 250$ & 1.210 & $c .000$ & 1.210 & 0.290 & $0.2094 F-03$ \\
\hline 129.930 & 1.210 & 5.000 & 1.210 & 0.290 & $0.2094 \mathrm{E}-03$ \\
\hline $13 \epsilon .5 C 0$ & 1.210 & C. 000 & 1.210 & 0.290 & $0.2094 E-33$ \\
\hline $251.5 \mathrm{cn}$ & 1.210 & $\operatorname{sen} 00$ & 1.210 & 0.290 & $0.2094 E-03$ \\
\hline $16 \mathrm{C} .750$ & 1.210 & C.000 & 1.210 & 0.290 & $0.2094 E-03$ \\
\hline $176.25 \mathrm{C}$ & 1.210 & C.000 & 1.210 & 0.290 & $0.2 C 94 E-03$ \\
\hline $184.33 c$ & 1.210 & C.000 & 1.210 & 3.290 & $0.2094 E-03$ \\
\hline 186.900 & 1.215 & $c .000$ & 1.215 & 0.340 & $0.2455 E-0.2$ \\
\hline 199.900 & 1.220 & 0.000 & 1.220 & $0.39 c$ & $0.2816 E-03$ \\
\hline 275.250 & 1.220 & C. $00 \mathrm{C}$ & 1. 220 & 0.390 & $0.2816 E-03$ \\
\hline 223.600 & 1.220 & 0.900 & 1.220 & 0.390 & $0.2816 E-0.3$ \\
\hline $231.90 n$ & 1.220 & C. 000 & 1.220 & 0.370 & $0.2816 E-03$ \\
\hline 247.800 & 1.225 & 0.000 & 1.225 & 2.440 & $0.3177 E-03$ \\
\hline 256.750 & 1.225 & C. DOC & 1. 225 & $0.44 n$ & $0.3177 E-03$ \\
\hline 271.750 & 1.225 & c.000 & 1.225 & 0.440 & $0.31>7 \mathrm{E}-0.3$ \\
\hline 282.100 & 1.220 & C. 000 & 1.220 & 0.390 & $0.2816 E-03$ \\
\hline $296.2 n n$ & 1.230 & $c .000$ & 1.230 & 0.490 & $0.3538 E-03$ \\
\hline 305.000 & 1.230 & c.000 & 1.230 & 0.490 & $0.3538 \mathrm{~F}-03$ \\
\hline 320.750 & 1.230 & 0.000 & 1. $23 \%$ & $0.49 n$ & $0.3538 E-23$ \\
\hline 331.800 & 1.230 & 0.020 & 1.230 & $0.49 c$ & $C .3538 E-03$ \\
\hline 344.600 & $1.24 n$ & C.000 & 1.240 & 0.590 & $0.4261 E-03$ \\
\hline $359.00 n$ & 1.235 & 0.000 & 1.235 & $0.54 c$ & $0.3900 E-03$ \\
\hline 375.100 & 1.235 & C. 000 & 1.235 & $0.54 n$ & $0.3900 E-03$ \\
\hline 381.900 & 1.235 & 0.100 & 1.235 & 0.540 & $0.3900 E-03$ \\
\hline $400.4 \mathrm{CC}$ & 1.243 & 0.000 & 1.240 & 0.590 & $0.4261 \mathrm{E}-\mathrm{n} 3$ \\
\hline 417.100 & 1.245 & c. 000 & 1.245 & 0.640 & $0.4622 E-03$ \\
\hline 441.700 & 1. 250 & C. 000 & 1. 250 & 0.690 & $0.4983 E-03$ \\
\hline $465.30 \mathrm{C}$ & 1.245 & C. 000 & $1 \cdot 245$ & 0.640 & $0.4622 E-03$ \\
\hline $475.40 n$ & 1.245 & C. 000 & 1.245 & 0.640 & $0.4622 E-03$ \\
\hline 498.500 & 1.250 & C.00C & $1.25 \mathrm{C}$ & 0.690 & $0.4983 E-03$ \\
\hline
\end{tabular}




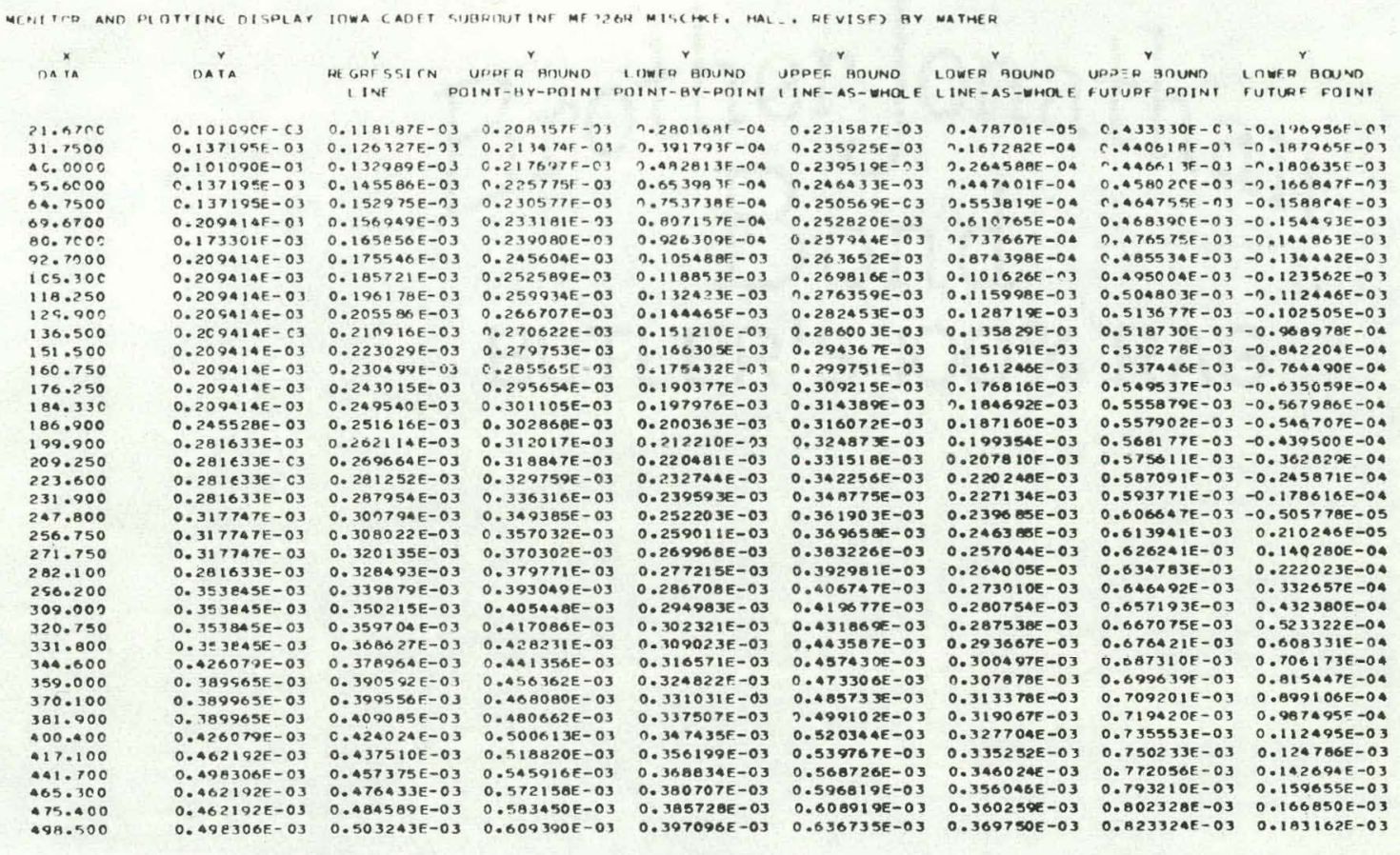

ORDINATE INTEPCEPT A OF REgRESSION LIAE ............. $0.1006876 E-03$ UPPER CONFIDENCE BOUND ON ORDINATE INTERCEPT A...... $0.1974913 E-03$ LOVEF CONFIDENCE LIMIT CN ORO INATE INTERCEPT A ....... $0.3883979 E-05$

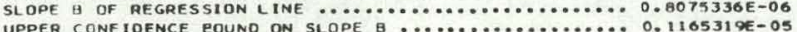
UPPER CONFIDENCE EOUND ON SLOPE B ................ 0.1165319E-05

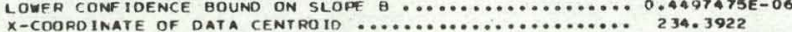

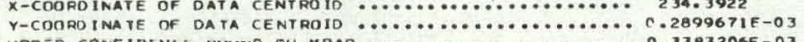

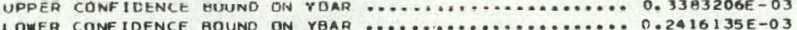

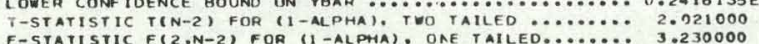
F-STATISTIIC F(2,N-2) FOR (1)-ALPHA). ONE TAILED......... 3.230000

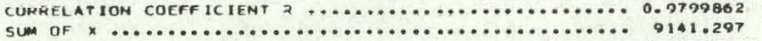
SUM of $r$. SUM of $x^{* * 2}$
SUM of $Y *{ }^{*}$

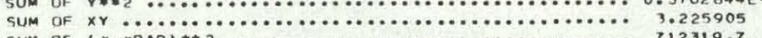

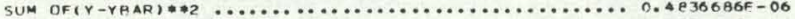

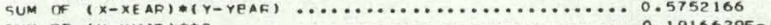

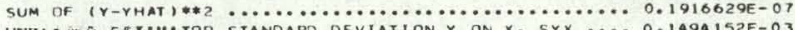

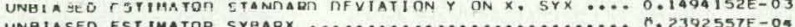

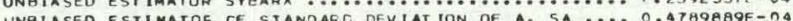
UNBIASED ESTIMATOR OF STANDAED DEVIATION OF A. SH $\ldots . .0 .1770342 E-06$ 
PE SULTS DF HIGH TEMHERATURE C.PEER TEST--

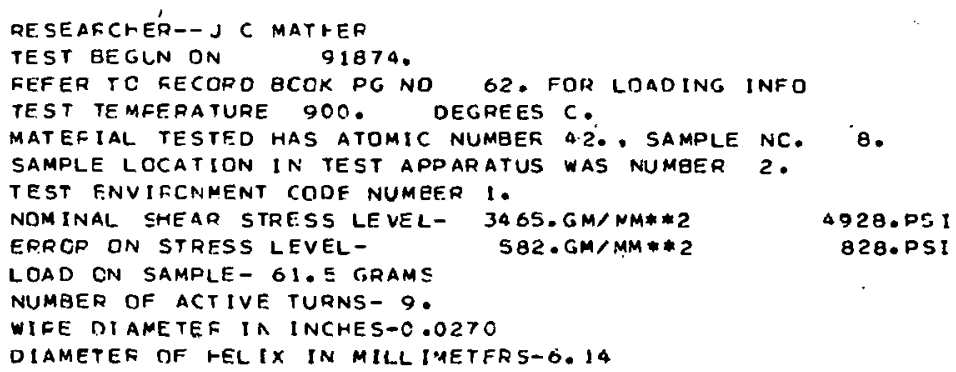

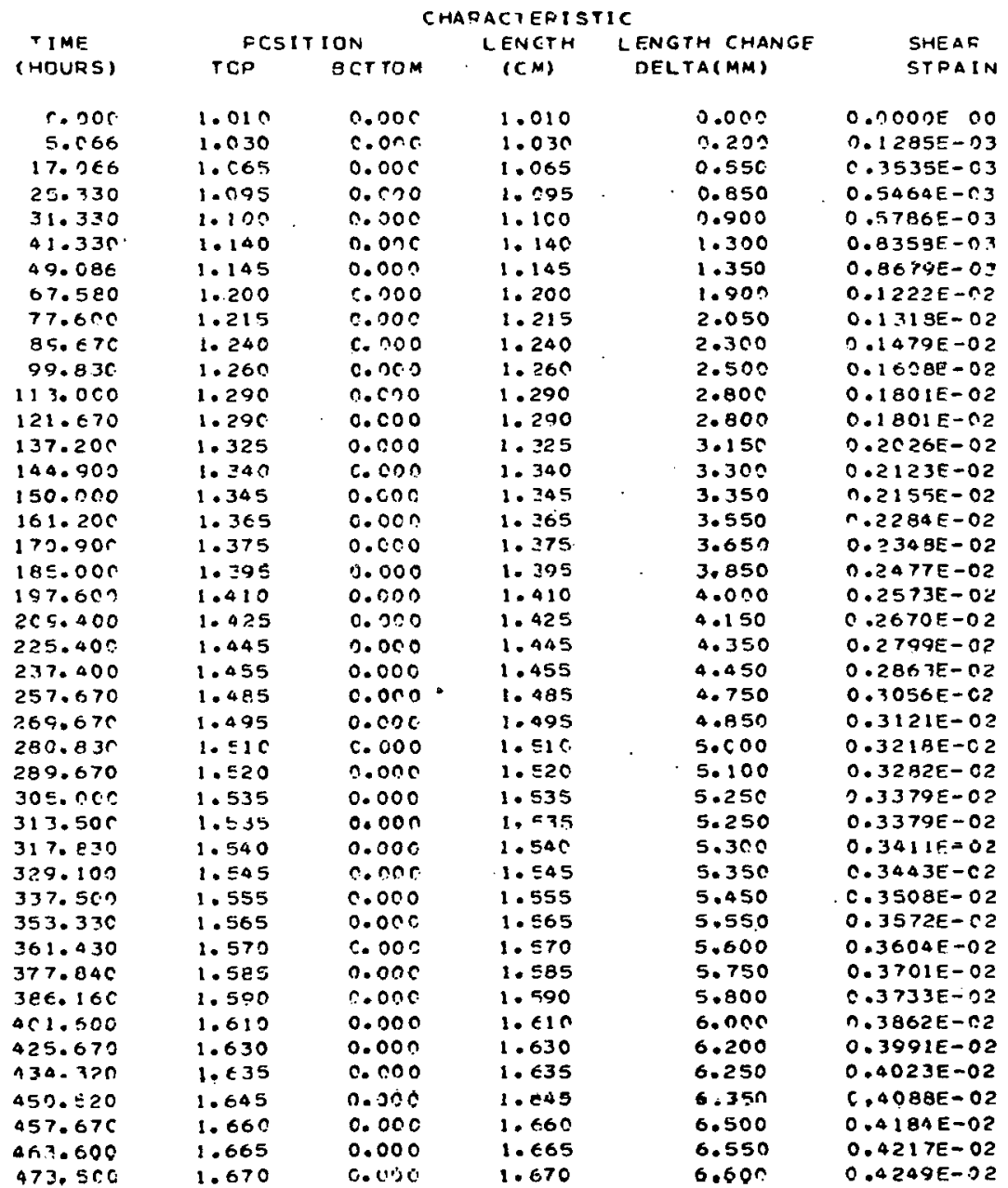




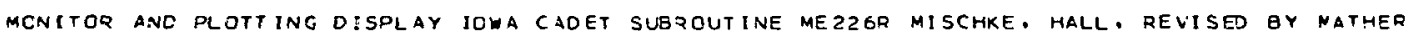

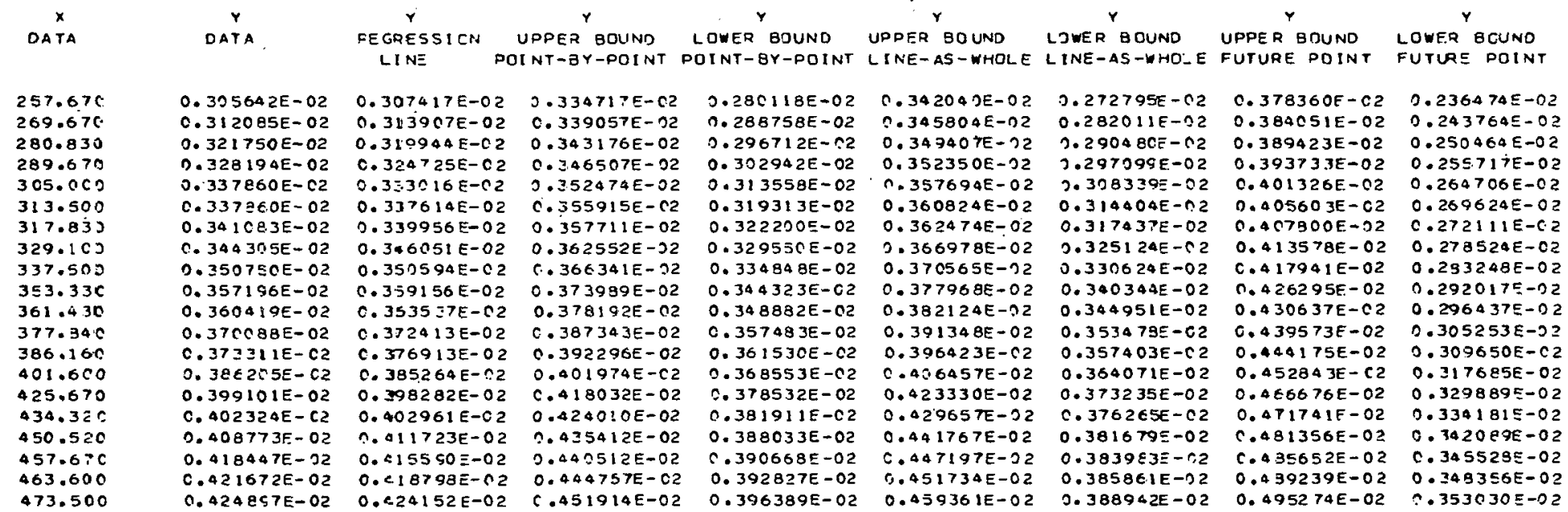

ORDINAT E INT ERCEPT A OF REGRESS ION LINE ............. $1680522 E-02$

UPPER CONFIOENCE BOUND ON ORDINATE INTERCEPT A ....... $0.2481110 E-02$

LOMEF CINF IDENCE LIMIT ON ORDINATE INTERCEPT A $\ldots \ldots \ldots . .8799334 E-03$

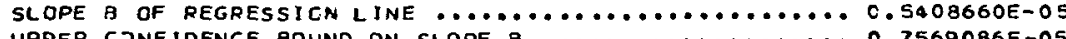

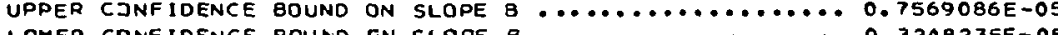

Y-COOPDINATE OF DATA CENTRODD

$Y$-COORD INATE OF DATA CENTFOID

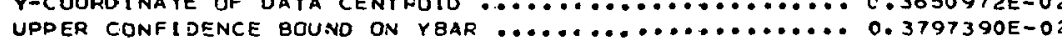

LOWER CCAFIJENCE EOUNO CN YEAF ......................

T-STATISTIC T(N-2) FOR (1-ALPHA), TVO TAILED .......... 2.101030

F-STATISTIC F $(2, N-2)$ FOR (1-ALFHA), ONE TAILED....... 3.550000

CORRELATION COEFFICIENT R ...........................9979733

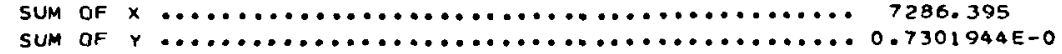

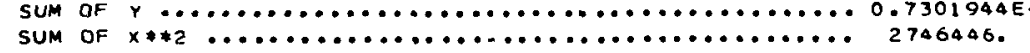

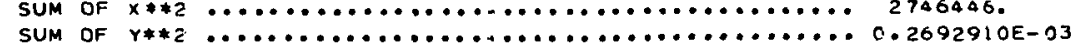

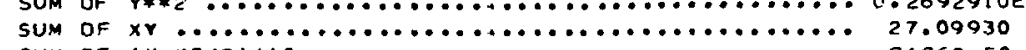

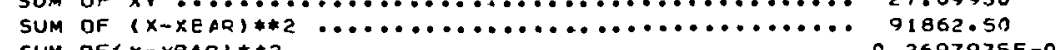

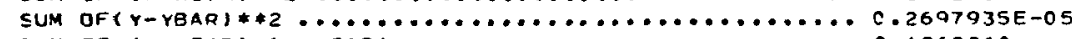

SUM JF $(X-X E A R)+(Y-Y E A R) \ldots \ldots \ldots \ldots \ldots \ldots \ldots \ldots \ldots \ldots \ldots \ldots \ldots \ldots \ldots .4968260)$

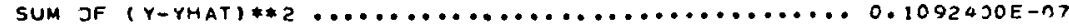

UNBIASEO ESTIMATOR STANCARD DEVIATION $Y$ ON $x_{\text {, SYX }}$ SY... $0.3116613 E-03$

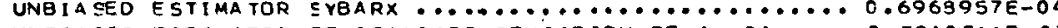

UNBIASED ESTIMATOF OF STANDARO DEVIIATION OF A. SA $\ldots . .30 .3810511 E-03$
UNBIASED ESTIMATOR CF STANDARO DEVIATION CF a, SE $\ldots . .0 .1028285 E-05$ 
FESULTS CF MIGH TENFFEATURL CPFFD TFST--

RESFAFCFER- J C MATHER

REFEF TO GECOPD BOOK PG NO TS. FOR LOADING INFO

TEST TEM MFEFATUFE 900 . DEGFEES $C$.

MATERIAL TESTEO HAS ATOMIC NUMAER A2. PAMPLE NC. 21.

SAMPLE LCCATION IN TEST APPARATUS WAS NUMBER ?.

TEST ENVIFONMENT CODE NUMBER 2.

NCMINAL STEAT STPFSS LEVEL- 3518.GM/MM\#2 2 5004.PSI

EPPOP ON STPESS LFVEL- $594 . G M / M M * t 2 \quad 845.051$

LOAD ON SAMPLS- GI. E GRAMS

NUMEER OF ACTIVF TURNS-10.

WIRE DIANETEF IN INCHES-2.0269

DIAMETCR OF HELIX IN MILLIMETERS-S. OT

\begin{tabular}{|c|c|c|c|c|c|}
\hline \multirow{3}{*}{$\begin{array}{l}\text { TIME } \\
\text { (HDURS) }\end{array}$} & \multicolumn{4}{|c|}{ CHAQACTERISTIC } & \multirow{3}{*}{$\begin{array}{l}\text { SHEAE } \\
\text { STRAIN }\end{array}$} \\
\hline & \multicolumn{2}{|c|}{ POSITION } & LENGTH. & \multirow{2}{*}{$\begin{array}{l}\text { LENGTH CHANGE } \\
\text { OELTA(MM) }\end{array}$} & \\
\hline & TOP & BCTTOM & $(C N)$ & & \\
\hline 0.000 & 1.400 & 0.009 & $1.4 n 0$ & 0.000 & $0.0000 E$ ON \\
\hline 7.528 & 1.425 & C. $30:$ & 1.425 & 0.250 & $0.1465 E-03$ \\
\hline 15.530 & 1.465 & $\cos \mathrm{c}$ & 1.465 & 0.650 & $0.3803 E-03$ \\
\hline $21.67 ?$ & $1.48 ?$ & $0.00 n$ & $1.48 C$ & 0.800 & $0.4688 E-03$ \\
\hline 31.750 & 1.510 & 0.006 & 1.510 & $1.10 n$ & $0.6446 E-C 3$ \\
\hline 40.000 & 1.535 & 0.00 ? & 1.535 & 1.350 & $0.7911 E-03$ \\
\hline $5 s .500$ & 1.570 & 0.700 & 1.570 & 1.700 & $0.9903 E-63$ \\
\hline 64.750 & 1.525 & 2.000 & 1.585 & 1.850 & $0.1 \cap 84 E-02$ \\
\hline $65 . \in 70$ & $1 . t 00$ & $c .030$ & $1 .+00$ & 2.000 & $C .1172 F-02$ \\
\hline Rn. 70 r & $1 . \leftarrow 25$ & 0.000 & 1.625 & $2.25 n$ & $0.1319 E .-02$ \\
\hline 22.700 & 1.6 .45 & n. $20 \mathrm{C}$ & 1.645 & 2.450 & $0.14 .36 E-0 ?$ \\
\hline 195.300 & 1.675 & $0.0 n n$ & $1 \cdot 6.75$ & 2.750 & $0.1612 F-02$ \\
\hline $11 \mathrm{~A} .25 \mathrm{C}$ & 1.695 & 0.000 & $1.0: 95$ & $2.95^{n}$ & $0.1729,-02$ \\
\hline 120.00 .0 & 1.725 & 0.000 & 1.725 & 3.250 & $c .19055-c 2$ \\
\hline $13 \% .500$ & 1.7 .30 & 0.260 & 1.730 & $3.30 ?$ & $0.1935 \mathrm{~F}-02$ \\
\hline $151.50 r$ & 1.755 & c.000 & 1.755 & $3.55 n$ & $0.2 C .81 F-r z$ \\
\hline $169.75 c$ & 1.770 & $c . c 00$ & $1.77 \mathrm{C}$ & $3.7 n C$ & $0.21690-02$ \\
\hline 176.250 & 1.75 .5 & c. 000 & 1.795 & 3.950 & $0.2316 \mathrm{E}-02$ \\
\hline $184.33 ?$ & 1.815 & 0.700 & 1.815 & 4.150 & $0.2433 \mathrm{~F}-0 ?$ \\
\hline $186.98 \mathrm{C}$ & 1.825 & c.0.n & 1.825 & $4.25=$ & $0.2492 \mathrm{E}-02$ \\
\hline 199.960 & 1.850 & c.ore & $1.25 n$ & 4.500 & $0.26395-02$ \\
\hline 209.250 & 1.860 & 0.0 . c & 1.860 & 4.600 & $0.2098 E-02$ \\
\hline $223.60 \mathrm{C}$ & 1.870 & 0.000 & $1.27 c$ & 4.702 & $0.2756 E-02$ \\
\hline 231.900 & 1.880 & 0.030 & 1.880 & 4.800 & $0.2815 E-02$ \\
\hline 247.800 & 1.890 & $2 . \sin c$ & 1.890 & 4.900 & $C .2874 E-02$ \\
\hline $256.75 \mathrm{C}$ & 1.905 & 0.000 & 1.905 & 5.050 & $0.2962 E-n 2$ \\
\hline $271.75 r$ & 1.915 & 0.000 & 1.915 & $5.15 ?$ & $0.3021 E-02$ \\
\hline 282.106 & 1.520 & $0.00 \mathrm{C}$ & 1.920 & 5.200 & $C .3050 E-03$ \\
\hline $296.20 \mathrm{C}$ & $1.43: 1$ & $c .000$ & 1.930 & 5.300 & $0.3109 E-02$ \\
\hline $309.00 ?$ & 1.045 & 0.002 & 1.945 & 5.450 & $13.3197 e-00$ \\
\hline $32 \mathrm{C} .75 \mathrm{C}$ & 1.555 & c.onn & 1.955 & $5.55 C$ & $0.3255 E-03$ \\
\hline 331 . Anc & 1.960 & 0.000 & 1.560 & $5.60 \mathrm{C}$ & $0.32 \mathrm{85E}-02$ \\
\hline 344.600 & 1.970 & $0.00 \mathrm{C}$ & 1.970 & 5.730 & $0.3344 E-02$ \\
\hline 355.0 .0 & 1.985 & 0.000 & 1.985 & $5.85 C$ & $0.3432 E-02$ \\
\hline .370 .100 & 1.990 & 0.000 & 1.990 & 5.900 & $0.3461 \mathrm{E}-02$ \\
\hline $381.900:$ & 2.000 & 0.000 & 2.000 & 6.000 & $0.352 \cap 5-02$ \\
\hline $402.4 C 6$ & $? .015$ & 0.000 & 2.015 & 6.150 & $0.36 \mathrm{CBE}-02$ \\
\hline 017.105 & 2.025 & 0.000 & 2.025 & 6.250 & $0.7667 E-02$ \\
\hline $411.7 n n$ & 2.0 .45 & 0.000 & 2. $C 45$ & 6.450 & $0.3784 E-02$ \\
\hline 465.300 & 2.065 & 0.000 & 2.005 & 5.650 & $0.3902 E-02$ \\
\hline 475.000 & 2.072 & 0.000 & 2.570 & 6.700 & $0.3031 F-4 . ?$ \\
\hline 908.500 & $2 . r 85$ & 0.000 & $2 . n 85$ & 6.850 & $0.4019 F-02$ \\
\hline
\end{tabular}




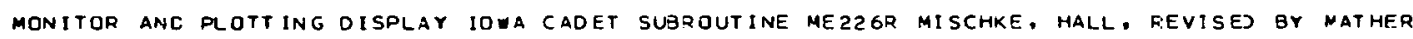

\begin{tabular}{|c|c|c|c|c|c|c|c|c|}
\hline DATA & OATA & $\begin{array}{l}\text { REGRESSION } \\
\text { LINE }\end{array}$ & $\begin{array}{l}\text { UPPER BOUND } \\
\text { POINT-GY - POINT }\end{array}$ & $\begin{array}{l}\text { LOWER BOUNO } \\
\text { POINT-EY-POINT }\end{array}$ & $\begin{array}{l}\text { UDPER BOUND } \\
\text { LINE-AS- WHOLE }\end{array}$ & $\begin{array}{l}\text { LOWER BOUND } \\
\text { LINE-AS-WHOLE }\end{array}$ & $\begin{array}{l}\text { UPPEE SOUNO } \\
\text { FUTURE POINT }\end{array}$ & $\begin{array}{l}\text { LOWER BOUND } \\
\text { FUTURE POINT }\end{array}$ \\
\hline & & $0.26<942 E-02$ & $0.290746 E-02$ & & $0.297091 E-02$ & $\begin{array}{l}0.236794 E-02 \\
0.242580 E-02\end{array}$ & $\begin{array}{l}0.332785 E-02 \\
0.336707 E-02\end{array}$ & $\begin{array}{l}2.201100 E-02 \\
0.205836 E-02\end{array}$ \\
\hline $\begin{array}{l}209.250 \\
223.600\end{array}$ & $\begin{array}{l}0.265756 E-02 \\
0.275628 E-02\end{array}$ & $\begin{array}{l}0.271272 E-02 \\
0.27 ? 916 E-02\end{array}$ & 0.29392 & $\begin{array}{l}0.248618 E-02 \\
0.25697 C E-C 2\end{array}$ & $\begin{array}{l}0.299963 E-02 \\
0.304444 E-02\end{array}$ & $\begin{array}{l}0.242580 E-02 \\
0.251388 E-02\end{array}$ & $\begin{array}{l}c .336 \\
c .302\end{array}$ & $\begin{array}{l}0.2058 \\
0.2130\end{array}$ \\
\hline $\begin{array}{l}223.600 \\
231.900\end{array}$ & $\begin{array}{l}0.275628 E-02 \\
0.281499 E-02\end{array}$ & $\begin{array}{l}0.277916 E-02 \\
c .281759 E-C 2\end{array}$ & $\begin{array}{l}0.258862 E-02 \\
0.301754 E-02\end{array}$ & $\begin{array}{l}0.25697 C E-C 2 \\
0.261763 E-02\end{array}$ & $\begin{array}{l}0.304444 E-02 \\
0.307 C 84 E-02\end{array}$ & $\begin{array}{r}0.251388 E-02 \\
3.256434 E-02\end{array}$ & $\begin{array}{l}0.302730 E-02 \\
0.346322 E-02\end{array}$ & $0.217196 \mathrm{E}-02$ \\
\hline 247.800 & $.287371 \mathrm{E}-\mathrm{C} 2$ & $0.28 \ni 121 E-02$ & $0.3073925-02$ & $0.27085 n E-02$ & $0.312261 E-02$. & $0.265980 E-02$ & $C .353171 E-C 2$ & $0.225071 E-C 2$ \\
\hline 256.7 & & C. $293265 E-02$ & 0.3106 & 0.275 & $n .315$ & & & \\
\hline 271.750 & $0.302050 E-02$ & $C \cdot 300210 E-J 2$ & $0.316197 E-02$ & $0.284222 E-02$ & $0.320458 E-02$ & $0.279961 \varepsilon-02$ & 0.363646 & -02 \\
\hline 282.100 & $0.304987 E-02$ & $0.305 C 02 E-02$ & $0.320: 57 E-c 2$ & $0.289847 E-02$ & $0.324196 E-02$ & $0.2858 \mathrm{CBE}-02$ & $0.368234 E-02$ & $0.291770 E-02$ \\
\hline & & $.311530 E-02$ & .32574 & $3.297318 E-02$ & $0.329531 E-02$ & $0.293530 E-02$ & $0.374543 E-0 ?$ & $0.248519 E-02$ \\
\hline $3 \mathrm{cg} .00 \mathrm{c}$ & & $c .31$ & & & & & $0.380330 E-02$ & $0.254583 \varepsilon-02$ \\
\hline 320.750 & $0.325 \leq 42 E-02$ & $C .322897 E-02$ & c. $336129 E$ & 0.309 & 0.3396 & 0.30 & 0.38 & \\
\hline 331.800 & $.328479 \varepsilon-02$ & $0.328013 E-02$ & $0.341104 E-02$ & $0.314923 E-C 2$ & $0.344593 E-02$ & 0.311 & $0.39 \mathrm{C}$ & $0.265244 E-02$ \\
\hline 600 & 02 & 0.33 & .34713 & 0.320 & 0.35055 & 0.317 & 0.396 & $0.271149 E-02$ \\
\hline & & -02 & 02 & & 0.357 & 0.3233428 & 0.403491 & $0.277723 E-02$ \\
\hline 370. & $0.346101 E-02$ & $0.345747 E-02$ & 0.359930 & $0.331563 E$ & $9.36=$ & & 0.408 & \\
\hline 381.900 & $0.351976 E-C 2$ & $C .351210 E-02$ & 0.36615 & & 0.37014 & 0.3322 & 0.414 & 0.2880 \\
\hline 400.400 & . $360789 E-02$ & $0.350776 E-02$ & $0.376234 E-02$ & 0.36 & $0.380621 E-02$ & $0.338931 E$ & 0.4233 & $0.296 .219 E-02$ \\
\hline & & & & & $0.390400 E-02$ & $0.344616 E$ & 0.431502 & $0.303514 E-02$ \\
\hline & & 0. & & & & & & \\
\hline & $C .390170 E-C 2$ & $0.389325 E-02$ & & & & & 0.455 & 0.3240 \\
\hline & $0.3931 \mathrm{CgE}-02$ & $0.394501=-c 2$ & $0.419372 E-02$ & $0.359630 \varepsilon-02$ & & $1 E-02$ & $37 E-0,2$ & $0.323265 E-02$ \\
\hline
\end{tabular}

OROINATE INTEECEPT A OF REGRESSI JN LINE ............ 0.1743870E-02

OROINATE INTEECEPT A OF REGRESSI JN LINE .................

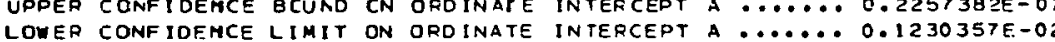
SLOPE B OF REGRESSICN LINE ....................... $0.4630092 E-05$ .

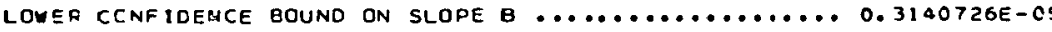

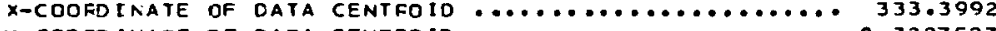

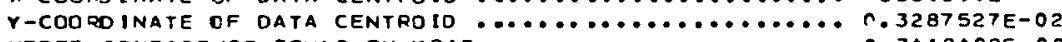

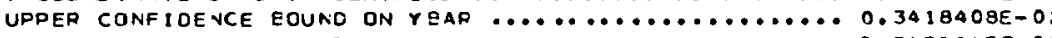

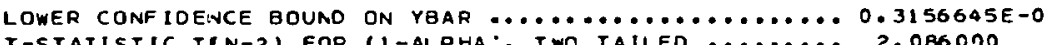
T-STATISTTC TRN-2) FOR TI -ALPHA. TU TAILED

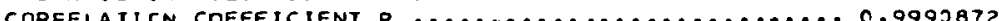

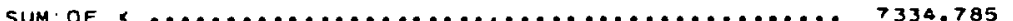

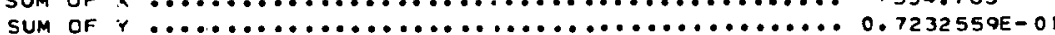

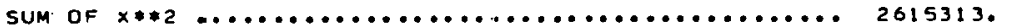

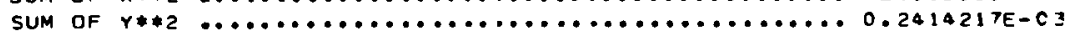

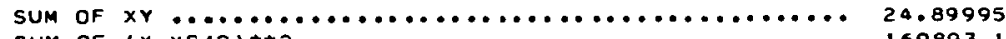

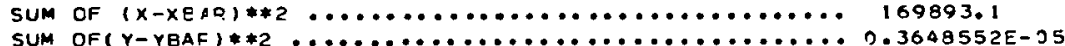

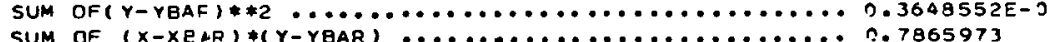

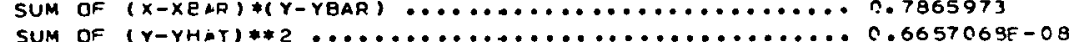

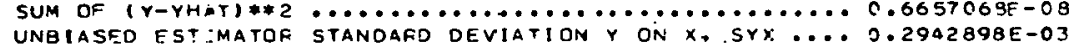

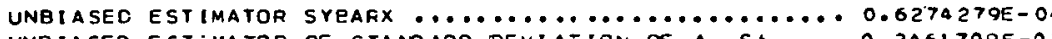
UNEIASED EST IMATOR OF STANOARD DEVIATION OF B. SB .... 0.7139817E-0 
RE SULTS OF HIGH TEMPERATURE CPEEP TEST--

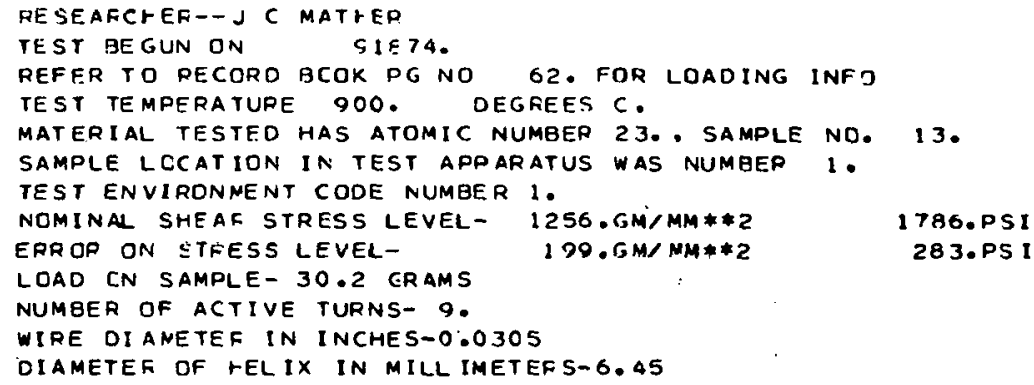

TIME (HOURS)

\begin{tabular}{|c|c|}
\hline 0.000 & 1.165 \\
\hline 5.066 & 1. 250 \\
\hline 17.066 & 1.610 \\
\hline $25.33 c$ & 1. EES \\
\hline 31.330 & $2 \cdot 105$ \\
\hline $41.33 c$ & 2.435 \\
\hline 49.026 & 2. $\in \in 5$ \\
\hline 67.580 & 3.195 \\
\hline 77.600 & 3.445 \\
\hline$B S, \in>0$ & 3.735 \\
\hline 99.830 & 3.960 \\
\hline 113.000 & 4.225 \\
\hline 121.670 & 4.385 \\
\hline $137.20 \mathrm{C}$ & 4.665 \\
\hline 144.900 & 4.725 \\
\hline 150.000 & 4.835 \\
\hline $1 \in 1.200$ & 5.005 \\
\hline 170.900 & 5.115 \\
\hline $185 . C C C$ & 5.280 \\
\hline 197.600 & 5.420 \\
\hline 205.400 & 5.545 \\
\hline 225.400 & 5.690 \\
\hline $237.4 \mathrm{cc}$ & $5.79 \mathrm{C}$ \\
\hline 257.670 & 5.960 \\
\hline 269.670 & c. .045 \\
\hline 280.830 & E. 120 \\
\hline ? 9.670 & 6.175 \\
\hline 305.000 & 6.275 \\
\hline 313.500 & 6.320 \\
\hline$\geq 17 . \varepsilon \geq c$ & 6. 350 \\
\hline $329.1 \mathrm{nn}$ & 6.405 \\
\hline $3.37 .50 \mathrm{C}$ & 6.450 \\
\hline 352.330 & $E . \leqslant 40$ \\
\hline $361.43 \mathrm{C}$ & 6.570 \\
\hline $377.64 r:$ & 6.650 \\
\hline 386.160 & 6.695 \\
\hline $401=6.0$ & 6.780 \\
\hline 425.676 & 6.890 \\
\hline $434 . \geq 20$ & 6.920 \\
\hline
\end{tabular}

CHARACTERISTIC BCT TOM

LENGTH LER DELTA (MM)

SHEAR

\section{$0.00 \mathrm{C}$}

$0.00 \mathrm{C}$
$\mathrm{c} .00 \mathrm{C}$

0.000

c. 000

$0.00 \mathrm{r}$

0.000

C. 00 ?

0.000

0.000

$0 . \operatorname{coc}$

C. on C

c. $00 \mathrm{C}$

0.000

0.000

0.000

0.000

0.000

c. oro

c. $00 \mathrm{C}$

0.000

0.000

0.000

$0.00 n$

0.000

0.000

0.000

0.000

c.000

0.000

0.200

0.000

0.000

c. 000

0.000

0.000

0.000

0.000

0.000
1.165

1.250

1.610

1. 285

2. 105

2. 435

2.665

3. 195

3. 445

3. 735

3. 560

4. 225

4. 385

4.665

4. 785

4. 935

5.005

S. 115

5. 280

5. 420

$5 . \$ 45$

5. 690

5.790

5.960

0.045

6. 120

6. 175

8. 275

6. 320

6. 350

6.405

6.450

6. 540

6.570

6. 650

6.695

6.780

6. BบU

6. 920

0.000
0.850
4.450
7.200
9.400
12.700
15.000
20.300
22.800
25.700
27.950
30.600
32.200
35.000
36.200
36.700
38.400
39.500
41.150
42.550
43.800
45.250
46.250
47.950
18.800
49.550
50.100
51.100
51.550
51.850
52.400
52.850
53.750
54.050
54.850
55.300
56.150
57.250
57.550

STFAIN

0.0 COOE OO

$0.5577 E-C 3$

$0.2922 E-02$

$0.4731 E-02$

C.618CE- 32

$0.8358 E-22$

$0.98 A O E-02$

$0.1340 E-C 1$

$0.1506 E-C 1$

$0.1700 E-C 1$

$0.1851 E-01$

$0.2029 E-01$

$0.2137 E-01$

$0.2326 E-01$

$0.2408 E-01$

$0.2442 E-C 1$

C.2557E-01

$0.2632 E-01$

$0.2745 E-01$

$0.2841 E-01$

$0.292 .7 E-01$

$0.3027 E-01$

$0.3096 E-01$

C.3214E-01

$0.3273 E-01$

$0.3325 E-01$

$0.3363 E-01$

C. $.3433 E-01$

$0.3464 E-01$

$0.3485 E-01$

$0.3524 E-C 1$

$0.3555 E-01$

$0.3618 E-01$

$0.3639 E-01$

$0.3696 E-01$

$0.3727 E-01$

C. 3787 E-0 I

0.3 ARFF- 01

0.3860 E- 01 


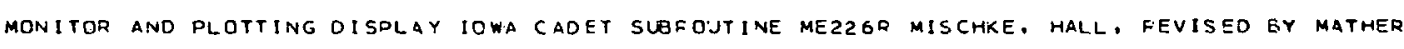

\begin{tabular}{|c|c|c|c|c|c|c|c|c|}
\hline DATA & CATA & $\begin{array}{l}\text { Y } \\
\text { REGRESIION } \\
\text { LINE }\end{array}$ & 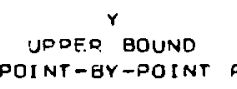 & $\begin{array}{l}\text { Y } \\
\text { LOWER BOUND } \\
\text { POINT-BY-POINT }\end{array}$ & $\begin{array}{l}{ }^{r} \\
\text { UPPER BOUND } \\
\text { LINE-AS-WHOLE }\end{array}$ & $\begin{array}{l}\text { LOWER BOUND } \\
\text { LINE-AS-WHOLE }\end{array}$ & $\begin{array}{l}\text { UPPER gOUND } \\
\text { UPUTRE POINT }\end{array}$ & $\begin{array}{l}\text { LOWER BOUNO } \\
\text { FUTURE POINT }\end{array}$ \\
\hline $5 . c c r$ & $0.343284 E-01$ & $c: \equiv 43875 \subseteq-01$ & $0.37 \leq I \leq 9 E-01$ & $0.317380 E-C 1$ & $0.377927 E-01$ & $0.309823 E-01$ & $C .404327 E-01$ & $0.283422 E-01$ \\
\hline 313.500 & $0.346427 E-C 1$ & $0.546881 \equiv-C 1$ & $c .370831 \mathrm{E}-01$ & $0.322891 \mathrm{E}-01$ & $0.377727 E-01$ & C. $316035 E-01$ & $83 E-01$ & 0.28748 \\
\hline & $348 \leq 24 E-01$ & $n .243413 E-n 1$ & $0.371208 E-01$ & $0.325617 E-01$ & $0.377711 E-01$ & $0.319114 E-? 1$ & $0.407338 E-01$ & $0.299487 E-01$ \\
\hline & $0.3 \subseteq 2373 E-$ & $0.552399 \mathrm{E}-01$ & 0.372 & & 0.378 & & $C .410281 E-01$ & $.294518 E-01$ \\
\hline 337.500 & $0.3 E \leqslant \leqslant 2 \leqslant E-01$ & C. $355370 E-01$ & $n .373537 E-01$ & 0.337 & 0.3787 & & $0.412664 E-C 1$ & $0.298076 E-01$ \\
\hline 353.330 & C. $3 \in 1 \& 39 E-01$ & $0.360970 E-01$ & $0.376984 \mathrm{E}-01$ & $0.374955 \varepsilon-01$ & $0.381553 E-21$ & $2.34038 \pi-.1$ & $0.417518 E-01$ & C. $334321 E-21$ \\
\hline & $0.363946 E-01$ & $0.363835 E-01$ & $0.379522 E-01$ & 3481488 & $0.383997 E$ & -01 & $0.420391 E-01$ & $0.307278 E-01$ \\
\hline & $0.365574 E-01$ & $0.369639 E-01$ & $0.386420 \mathrm{E}=$ & $0.352858 \mathrm{E}$ & $0.391207 E$ & .01 & $0.426509 E-01$ & $0.3127 \in 9 E-01$ \\
\hline 150 & 0.372 & 0.3725 & & & & & & \\
\hline $401.6: 0$ & $0.37 E T A C E-21$ & $0.378043 E-01$ & $\because .399659 E-\cap 1$ & $0.356428 E-01$ & 3.4058 & $C .350262 E-01$ & $0.436522 E-01$ & $0 . \geq 19 \leq \in A E-C_{1}$ \\
\hline 425.6 .70 & $0.386519 \mathrm{E}-01$ & 0.386557 & 0.41514 & & $0.423298 E-01$ & $0.3498168-01$ & $C .447955 E-01$ & $0.325159 E-31$ \\
\hline & $399 \leqslant \Delta 4 E-O I$ & $39617 E-01$ & $20565 E-$ & $58268 \mathrm{E}-\mathrm{r} 1$ & $E-01$ & $0.349326 E-01$ & $0.452349 E-01$ & $0.326885 E-01$ \\
\hline
\end{tabular}

ORDINATE INTERCEPT A OF REGRESSION LINE ........... $0.2359923 E-C$ CI UPDER CONFIDENCE GCUND ON ORDINATE INTERCEP A............ 0.3725196 E-C1 LOWER CONFIDENCE LIMIT ON ORDINATE INIERCEPT A ....... $0.9936512 E-02$ SLOPE 9 CF REGRESSION LINE .......................

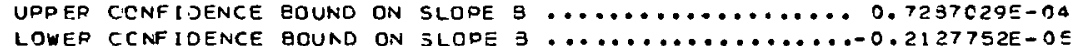
LOWER CCNFIDENCE BOUND ON SLODE $3 \ldots \ldots \ldots \ldots \ldots \ldots \ldots, \ldots, 0.2127752 E-0$

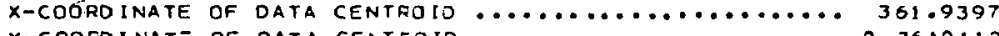

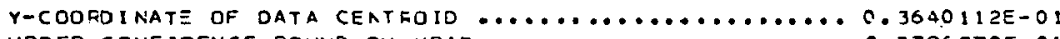

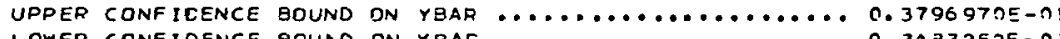

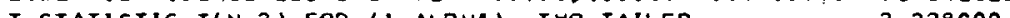
F-STATISTIC FI 2 N-2) FCF (1-ALPHA), ONE TAILED......... 2.228000 CORRELATICN COEFFICIENT Q ........................ 0.9994625 SUM OF $\times$

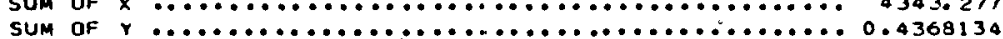
.

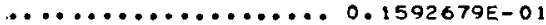

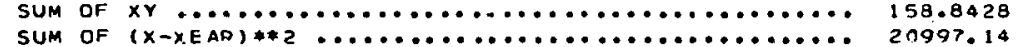

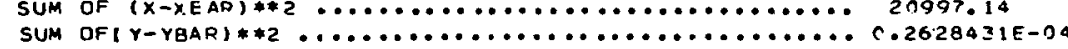

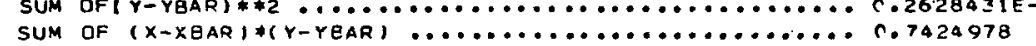

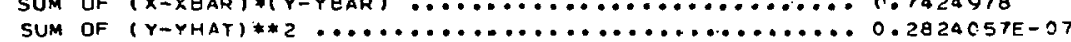
UNBIASED ESTIMATOR STANDARD DENIATION $Y$ ON $X$. SYX .... n.2433852E-D2

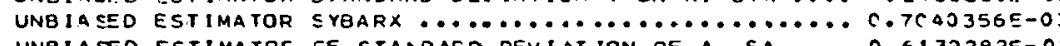
UNBIASEO ESTIMATOR OF STANDAFD DEVIATION OF A. S9.... 0.1683080E-OA 


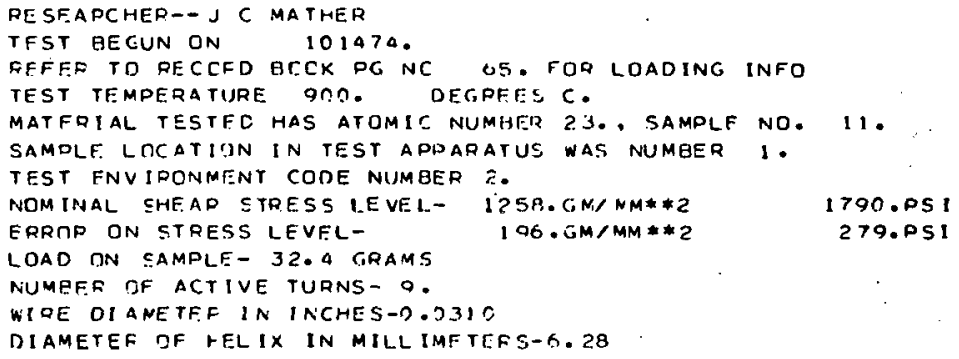

\begin{tabular}{|c|c|c|c|c|c|}
\hline \multirow{3}{*}{$\begin{array}{l}\text { TIMF } \\
\text { (HOUPS) }\end{array}$} & \multicolumn{4}{|c|}{ CHARACTERISTIC } & \multirow{3}{*}{$\begin{array}{l}\text { SHEAR } \\
\text { STPA IN }\end{array}$} \\
\hline & \multicolumn{2}{|c|}{ POSITION } & LEN GTH & LENGTH CHANGF & \\
\hline & TOP & BCTTOM & $(C N)$ & DELTA(MM) & \\
\hline $2.0 \mathrm{CC}$ & 1.260 & 0.000 & 1.260 & 2.090 & O.JCつDE \\
\hline 7.530 & 1.280 & c. $=0$. & $1 \cdot 280$ & $0.2 n r$ & $0.1425 E-03$ \\
\hline 15.530 & 1.345 & 0.000 & $1 \cdot .345$ & 0.850 & $0.6055 E-0 ?$ \\
\hline 21.670 & 1.545 & c. 000 & 1.545 & 2.859 & $0.2 C 31 E-n 2$ \\
\hline $31.7 \leq 0$ & 1.795 & c.ono & $1 \cdot 735$ & 5.350 & $0.3815 F-02$ \\
\hline 40.000 & 1.095 & c.nor. & 1.995 & 7.350 & $0.5245 E-.22$ \\
\hline $5 E .6 C C$ & 2.315 & $0.00 \mathrm{c}$ & 2.315 & $10.55 \%$ & $0.7535 E-22$ \\
\hline $64.75 n$ & 2.530 & 0.000 & 2.530 & $12.70 n$ & $0.9077 E-02$ \\
\hline 69.670 & 2.655 & c.coc & 2.655 & 13.950 & $0.9975 E-02$ \\
\hline $8 n .700$ & $2.93 \mathrm{C}$ & 0.000 & 2.932 & 16.700 & $0.1195 E-01$ \\
\hline 92.700 & 3.215 & $\operatorname{coc} 2$ & $? \cdot 215$ & $19.55 n$ & $0.1401 E-01$ \\
\hline 105.300 & 3.465 & $0.00 \mathrm{C}$ & 3.455 & 22.050 & $0.15825-01$ \\
\hline 118.750 & 3.720 & 0.000 & 3. 720 & 24.600 & $0.1767 E-01$ \\
\hline $129.96 ?$ & 3.035 & 6.000 & 3.9 .35 & $26.75 r$ & $0.1923 E-01$ \\
\hline 136.500 & 4.045 & .0 .000 & 4.045 & 27.850 & $0.2004 E-01$ \\
\hline 151.50 .0 & 4.315 & 0.000 & $4 \cdot \geq 15$ & 30.550 & $0.2201 E-01$ \\
\hline $16 C .750$ & 4.480 & 0.000 & 4.486 & 32.200 & $0.2322 E-01$ \\
\hline 176.250 & 4.730 & $0 . n e n$ & $4 \cdot 730$ & $34 \cdot 700$ & $0.2506 E-01$ \\
\hline 184.336 & 4. $8 \in 5$ & 5.200 & 4.265 & 36.050 & $0.260 .6 E-91$ \\
\hline 186.900 & 4.925 & $0.00 \mathrm{C}$ & 4. 925 & 36.650 & $0.2650 \varepsilon-01$ \\
\hline $199.90 \mathrm{C}$ & 5.150 & 0.000 & 5.150 & 39.900 & $0.2817 E-01$ \\
\hline $239.25 n$ & 5.255 & 0.000 & $-5 . \geq 55$ & 39.9 .50 & $0.2895 E-01$ \\
\hline $223.6 \mathrm{co}$ & 5.450 & 0.000 & 5.450 & $41.9 ? 0$ & $0.3040 E-01$ \\
\hline 231.900 & 5.550 & 0.000 & 5. $\leq 50$ & .42 .900 & $0.3115 E-01$ \\
\hline 247.800 & 5.755 & 0.0 .20 & 5.755 & 44.950 & $? .3269 E-01$ \\
\hline 256.750 & 5.865 & 0.000 & 5.265 & 46.050 & $0.3352 E-C 1$ \\
\hline 271.750 & 6.055 & $0.20 \mathrm{C}$ & 6.053 & 47.950 & $0.349 .5 E-01$ \\
\hline $28 \bar{c} \cdot 100$ & 6.170 & 0.000 & 6.170 & 49.100 & $0.3582 E-01$ \\
\hline $296.2 n c$ & 6.352 & 0.000 & 6.250 & $50 \cdot 900$ & $0.3719 E-01$ \\
\hline 309.000 & E. 425 & 0.000 & 6.405 & $63.25 n$ & 0. उA?ZE-O \\
\hline 320.750 & 6.627 & 0.000 & 6.620 & 53.600 & $0.3925 E-01$ \\
\hline $331 . \varepsilon \mathrm{CC}$ & 6.740 & $0.0 .0=$ & 6.740 & $54.8 \div 2$ & $0.4017 E-01$ \\
\hline $344.60 r$ & 6.880 & 0.000 & 6. 280 & $56.20 \mathrm{C}$ & $0.4125 E=n 1$ \\
\hline
\end{tabular}




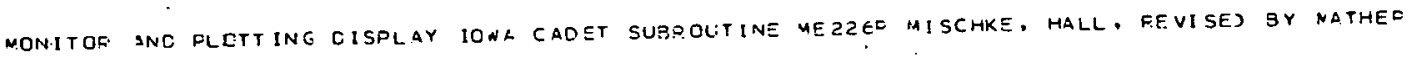

\begin{tabular}{|c|c|c|c|c|c|c|c|c|}
\hline $\begin{array}{c}x \\
D A T A\end{array}$ & $\stackrel{Y}{\text { DATA }}$ & $\begin{array}{c}Y \\
\text { REGE SSIICN } \\
L: N \equiv\end{array}$ & $\begin{array}{l}\text { UPOER ENUND } \\
\text { OINT-BYTDOINT }\end{array}$ & $\begin{array}{l}\text { LOUER BDUND } \\
\text { POINT-OY-POINT }\end{array}$ & $\begin{array}{l}\text { UPPER BOUND } \\
\text { LINE-AS-WHOLE }\end{array}$ & $\begin{array}{l}\text { LOWER FOUND } \\
\text { LINE-AS-WHOLE }\end{array}$ & $\begin{array}{l}\text { UPPEP BOUND } \\
\text { FUTJRE POINT }\end{array}$ & $\begin{array}{l}\text { LOWER BOUND } \\
\text { FUTURE POINT }\end{array}$ \\
\hline 0.095 & $0.281691 E-C 1$ & $0.232548 E-01$ & $\because 3121.75 E-01$ & & 2. & $\begin{array}{l}0.244572 E-01 \\
256545 E-01\end{array}$ & $\begin{array}{l}0.347384 E-01 \\
0.354716 E-C 1\end{array}$ & $\begin{array}{l}0.21>713 E-01 \\
0.22718 E-01\end{array}$ \\
\hline 10 & $1514 E-$ & 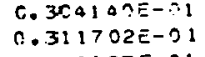 & $\begin{array}{l}.327226 E-01 \\
.33279 \mathrm{CE}-01\end{array}$ & $\begin{array}{l}3.281254 E-C .1 \\
9.290614 E-c 1\end{array}$ & $\begin{array}{l}0.333 \\
2.359\end{array}$ & $0.28467 ?$ & 0.37 & $296 E-21$ \\
\hline 7. $3 \approx 0$ & $68705-01$ & C. $326187 E-01$ & $\begin{array}{l}C .33279 C E-011 \\
C .344153 E-C 1\end{array}$ & $\begin{array}{l}.290614 E-C 1 \\
\therefore .308222 E-01\end{array}$ & & -1 & c. $38 \in 59$ & $B 3 E-01$ \\
\hline 256.750 & $235166 E-01$ & $C . \equiv 34341 E-01$ & $0.3511: 5 E-\cap 1$ & $0.317563 E-01$ & 0.355842 & 0.312 & 01 & -01 \\
\hline $271.7 \equiv 0$ & 0.349 & $C . \geq 43007 E-01$ & $0.364 c=35$ & & 01 & 0.32 & 01 & $0.283159 E-01$ \\
\hline & $n .3$ & $0 . \equiv 5$ & $0.373381 E$ & $n .340$ & 1 & $\therefore 336$ & & 0.29 \\
\hline$c 0$ & & $0 . \Sigma 7$ & S15E- & 52050 & 21 & 0.346 & 0.43 & $0.359798 E-01$ \\
\hline . & 0. & $c .58$ & & 0.3611 & a. & & & $c: 32^{n} 651 E-01$ \\
\hline & 0. & $\therefore .5926485$ & & $E-01$ & $\therefore .42$ & & 01 & $0.330339 E-0.1$ \\
\hline 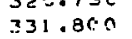 & $0.401737 E-01$ & 政1 & c. & & & $68 E-n 1$ & & $0.339222 E-n 1$ \\
\hline & & & 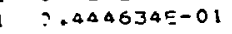 & $2 v=-0$ & & $92 \equiv-c 1$ & $0.479503 E-01$ & $0.349251 E-01$ \\
\hline
\end{tabular}

$.1004304 E-01$

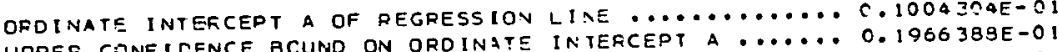

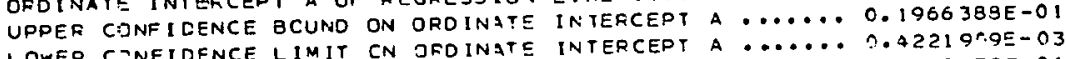

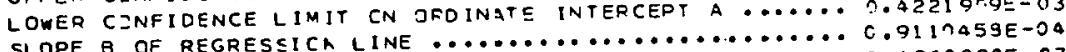

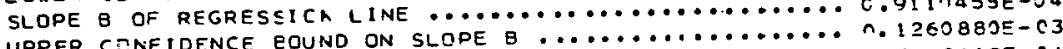

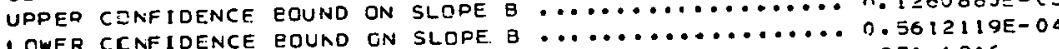

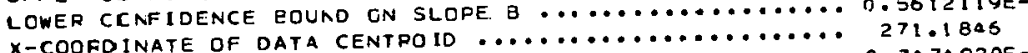

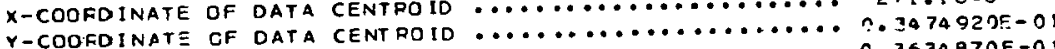

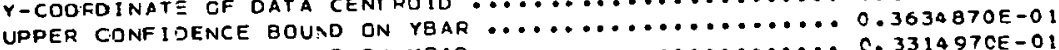

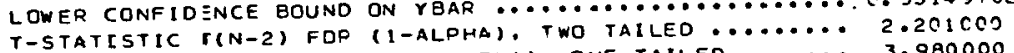
T-STATISTIC R(N-2) HOP (1-ALPHA) ONE TALLED........ 3.980000

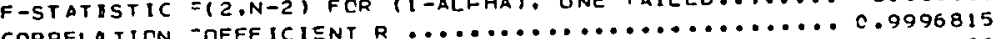

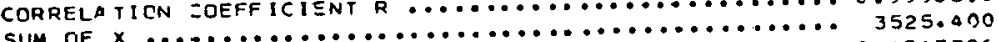

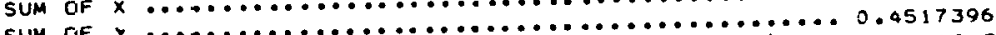

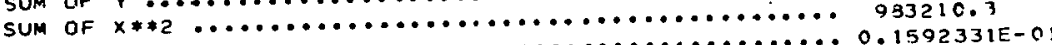

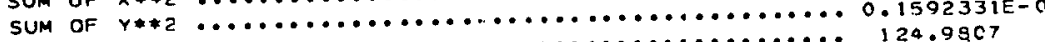

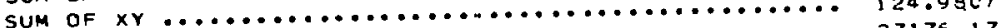

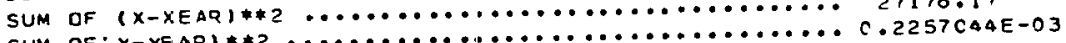

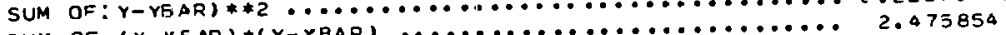

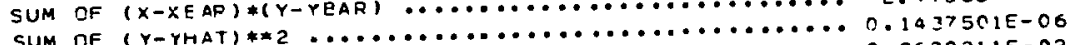

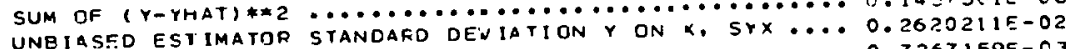
UNBIASED ES IMATOF SYEARX ........................... $0.7267159 E-6$

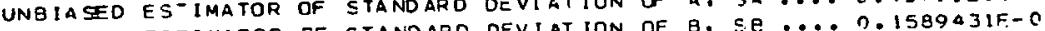


X. APPENDIX C. POLYNOMIAL EXPRESSIONS FOR SHEAR STRAIN $(\gamma)$ AND SHEAR STRAIN RATE $(\dot{\gamma})$ AS FUNCTIONS OF TIME $(t)$ IN HOURS

For molybdenum in vacuum environment:

$$
\begin{aligned}
\gamma= & (0.373)\left(10^{-4}\right)+(0.1946)\left(10^{-4}\right)(t)-(0.424)\left(10^{-7}\right)\left(t^{2}\right) \\
& +(0.512)\left(10^{-10}\right)\left(t^{3}\right)-(0.186)\left(10^{-13}\right)\left(t^{4}\right) \\
\dot{\gamma}= & (0.1946)\left(10^{-4}\right)-(0.848)\left(10^{-7}\right)(t)+(1.536)\left(10^{-10}\right)\left(t^{2}\right) \\
& -(0.744)\left(10^{-13}\right)\left(t^{3}\right)
\end{aligned}
$$

For molybdenum in hydrogen environment:

$$
\begin{aligned}
\gamma= & (0.618)\left(10^{-4}\right)+(0.1796)\left(10^{-4}\right)(t)-(0.308)\left(10^{-7}\right)\left(t^{2}\right) \\
& +(0.1287)\left(10^{-10}\right)\left(t^{3}\right)+(0.1777)\left(10^{-13}\right)\left(t^{4}\right) \\
\dot{\gamma}= & (0.1796)\left(10^{-4}\right)-(0.616)\left(10^{-7}\right)(t)+(0.3861)\left(10^{-10}\right)\left(t^{2}\right) \\
& +(0.7108)\left(10^{-13}\right)\left(t^{3}\right)
\end{aligned}
$$

For vanadium in vacuum environment:

$$
\begin{aligned}
\gamma= & (-0.161)\left(10^{-2}\right)+(0.275)\left(10^{-3}\right)(t)-(0.866)\left(10^{-6}\right)\left(t^{2}\right) \\
& +(0.144)\left(10^{-8}\right)\left(t^{3}\right)-(0.923)\left(10^{-12}\right)\left(t^{4}\right) \\
\dot{\gamma}= & (0.275)\left(10^{-3}\right)-(1.732)\left(10^{-6}\right)(t)+(0.432)\left(10^{-8}\right)\left(t^{2}\right) \\
& -(3.728)\left(10^{-12}\right)\left(t^{3}\right)
\end{aligned}
$$

For vanadium in hydrogen crivironment:

$$
\begin{aligned}
\gamma= & (-0.199)\left(10^{-2}\right)+(0.179)\left(10^{-3}\right)(t)-(0.122)\left(10^{-7}\right)\left(t^{2}\right) \\
& -(0.199)\left(10^{-8}\right)\left(t^{3}\right)+(0.295)\left(10^{-11}\right)\left(t^{4}\right) \\
& -(0.202)\left(10^{-14}\right)\left(t^{5}\right) \\
\dot{\gamma}= & (0.179)\left(10^{-3}\right)-(0.244)\left(10^{-7}\right)(t)-(0.357)\left(10^{-8}\right)\left(t^{2}\right) \\
& +(1.18)\left(10^{-11}\right)\left(t^{3}\right)-(1.01)\left(10^{-14}\right)\left(t^{4}\right)
\end{aligned}
$$

